\title{
The Future of European Onshore Wind Energy Potential: Detailed Distribution and Simulation of Advanced Turbine Designs
}

\author{
David Severin Ryberg ${ }^{\mathrm{a}}$, Dilara Gulcin Caglayan ${ }^{\mathrm{a}}$, Sabrina Schmitt ${ }^{\mathrm{a}}$, Jochen Linßen ${ }^{\mathrm{a}}$, Detlef Stolten ${ }^{\mathrm{a}, 1}$, Martin \\ Robinius $^{\mathrm{a}}$ \\ ${ }^{a}$ Institute for Electrochemical Process Engineering (IEK-3), Forschungszentrum Jülich GmbH, Wilhelm-Johnen-Str., D-52428, Germany
}

\begin{abstract}
Considering the need to reduce greenhouse gas emissions, onshore wind energy is certain to play a major role in future energy systems. This topic has received significant attention from the research community, producing many estimations of Europe's onshore wind potential for capacity and generation. Despite this focus, previous estimates have relied on distribution assumptions and simulation schemes that summarily under predict both the amount of available future wind capacity as well as its performance. Foremost in this regard is the common use of contemporary, or at least near-future, turbine designs which are not fitting for a far-future context. To fulfill this role, an improved, transparent, and fully reproducible work flow is presented for determining European onshore wind potential. Within a scenario of turbine cost and design in 2050, 13.5 TWof capacity is found to be available, allowing for $34.4 \mathrm{PWh}$ of generation. By sorting the explicitly-placed potential generation locations by their expected generation cost, national relations between turbine cost and performance versus a desired capacity are exposed. In this way, it is shown that all countries possess some potential for onshore wind energy generation below $4 €_{\mathrm{ct}} \mathrm{kWh}^{-1}$ and, furthermore, that it is unlikely for these costs to exceed $6 €_{\mathrm{ct}} \mathrm{kWh}^{-1}$.
\end{abstract}

Keywords: Renewable energy systems, land eligibility, Onshore wind energy, technical potential, economic potential, simulation

\section{Introduction}

In light of the established need to reduce carbon emissions and stem the tide of climate change [1, 2], it is increasingly apparent that variable renewable energy sources (VRES) such as onshore wind energy will play a large role in future energy systems. Indeed, the European Union (EU) has set the long term target of $80 \%$ to $95 \%$ reduction of green house gas emissions by 2050 [3]. To achieve this target, Germany, for example, has pledged to become nearly completely powered by renewable generation by 2050 [4]; which as discussed by Robinius et al. [5, 6]is sure to include reliance on onshore wind energy among other VRES sources. Yet even with these action plans in mind, the outlook of onshore wind energy remains unclear; especially in regards to the cost and design of future wind turbines, the extent by which they will be deployed, and the spatial distribution of the emerging capacity. The outcome of these qualities depends heavily on the progression of the wind energy industry in the coming years [7] and furthermore on the ever-evolving sociopolitical perspectives of policy makers, local populations and other stakeholders [8]. Therefore, despite the uncertainty inherent to this topic, it is of high importance to European policy makers and researchers to continually hone estimations for the potential of wind energy generation and associated costs in future time frames using the most up-to-date information.

Without a doubt, wind energy's role in the future European energy system is a commonly discussed topic in the literature; something which is clearly shown by the many future capacity scenarios proposed by various research

\footnotetext{
Email address: s.ryberg@fz-juelich.de (David Severin Ryberg)

${ }^{1}$ Chair for Fuel Cells, RWTH Aachen University, c/o Institute for Electrochemical Process Engineering (IEK-3), Forschungszentrum Jülich GmbH, Wilhelm-Johnen-Str., D-52428, Germany
} 
organizations. The EU's E-Highway 2050 project [9], for example, employed a mix of optimization and stake-holder review techniques to develop 5 future scenarios for Europe that encompass a wide range of possible future European energy systems. They find that, in 2050, the requirement for onshore wind capacity in Europe ranges from a low of $262 \mathrm{GW}$, in their 'Fossil \& Nuclear' scenario, to a high of $760 \mathrm{GW}$ in their "100\% RES" scenario [10]. Similarly, when projected to 2050, the International Energy Agency (IEA) predicts that OECD Europe will need $607 \mathrm{GW}$ in their 'New Policies' scenario and 742 GW in their '450' scenario [11]. The Global Wind Energy Council (GWEC) predicts $642 \mathrm{GW}$ and $703 \mathrm{GW}$ for OECD Europe in their 'Moderate' and 'Advanced' scenarios, respectively [12]. The European Climate Foundation (ECF) assumes a higher reliance on solar energy, and so only predicts a need for $245 \mathrm{GW}$ of onshore wind capacity in Europe in their ' $80 \%$ RES' scenario and only $140 \mathrm{GW}$ in their 'Baseline' scenario [13]. To fulfill these projected capacities, the 2050 cost of turbines is also commonly estimated. In comparison to today's average cost of $1450 € \mathrm{~kW}^{-1}$ [14], examples of estimated future costs are $1321 € \mathrm{~kW}^{-1}$ by GWEC [12], $1160 € \mathrm{~kW}^{-1}$ by EMD International [15], $1100 € \mathrm{~kW}^{-1}$ by the Joint Research Center (JRC) [16], 1074 € $\mathrm{kW}^{-1}$ by the European Commission [17], $1000 € \mathrm{~kW}^{-1}$ by the International Renewable Energy Agency [18], and between 900 $-1200 € \mathrm{~kW}^{-1}$ by ECF [13]. There is also clear direction regarding the momentum of future turbine designs, with increasing capacities, hub heights, and rotor diameters alongside decreasing specific powers [7].

To determine the feasibility of these wind energy outlooks, multiple authors have proposed methods which can perform wind potential estimations over a generic spatial context. While it does not present all such approaches which can be found, Table 1 shows a brief overview of studies which cover the most commonly used techniques. Each approach can be characterized using four criteria; input weather data, wind speed adjustment procedure, assumed turbine designs, and distribution technique. Most of the presented studies have used a climate model to provide time series weather variables, except for Robinius [19] who used measured weather station data. Generally hourly data input is employed, although in some case 3-hourly or even monthly averages is chosen. In all cases, the input weather data must be adjusted to the local context of a turbine being simulated; which should be done both horizontally and vertically relative to Earth's surface. Horizontally, a large variety of approaches are taken ranging from no adjustment, to interpolation between climate model grid points, to wind speed distribution matching between high resolution wind statistics datasets and low resolution climate model time series data [20]. Vertically, in almost all cases a logarithmic wind profile is assumed, although the method selected to determine roughness lengths vary widely. Zappa \&

Broek [21], for example, assume a constant roughness length, while Staffel and Pfenninger [22] compute a projection factor from multiple climate model heights via time-sensitive regression. There is also much variety in turbine designs which are assumed. With the exception of Robinius [19], all methods presented in Table 1 have chosen to employ contemporary, or at most near-future, turbine designs which typically range in capacity from 3 to $4 \mathrm{MW}, 100$ to $125 \mathrm{~m}$ hub height, and 430 to $320 \mathrm{~W} \mathrm{~m}^{-2}$ specific powers. An indication of historic in Table 1 signifies that the characteristics of actual turbine installations are used. Finally, most of the studies presented above performed a land eligibility analysis in order to determine where turbines can be placed and, on top of this result, assume a suitability factor which can range between $6 \%$ [21] to between 50 and $100 \%$ [23, 24]. Afterwards, a power density is often assumed, ranging between 4 and $18 \mathrm{MW} \mathrm{km}^{-2}$. In order to avoid the uncertainties in suitability and power density assumptions, few studies have used an explicit turbine placement scheme which can better distribute turbines within eligible areas $[25,19]$.

Each study presented in Table 1 has merit, although each also overlooks one or more key considerations which directly influence final potential estimations. The use of climate model data with an overly-simplified adjustment scheme, for instance, is not able to capture the small-scale weather dynamics leading to an under prediction observed wind speeds [26]. Moreover, treating near-surface climate model outputs as point-values, instead of values representative of a large contextual area, followed by directly projecting these wind speeds to a hub height can result in a divergence of wind speeds at high altitudes as opposed to the convergence which is expected by climate science [27]. As a result, projections performed in this manner are likely to underestimate the wind profile at low-roughness locations, where turbines are most likely to be installed, while at the same time overestimating the profile at highroughness locations. Furthermore, the use of contemporary turbine designs will certainly not capture the improved performance expected by future turbine designs $[16,7]$, and assumptions of land suitability and power density are both highly speculative and don't consider topology of the eligible areas. Explicit placement procedures can make better use of the available areas, although none have been consistently applied to the entire European context within a single analysis. As a result, European wind energy potential estimations performed in the past have arguably underestimated total potentials by means of low wind speed estimation, under prediction of future turbine performance, or 
Table 1: Summary of a few approaches taken to estimate wind energy generation. When a study used multiple values for a reported quantity, the average is reported here.

\begin{tabular}{|c|c|c|c|c|c|}
\hline \multirow[t]{2}{*}{ Study } & \multirow{2}{*}{$\begin{array}{c}\text { Data Resolution } \\
\text { Temporal } \\
\text { Spatial }\end{array}$} & \multicolumn{2}{|c|}{ Wind Adjustment } & \multirow{2}{*}{$\begin{array}{c}\text { Turbine Design } \\
\text { Capacity } \\
\text { Hub Height } \\
\text { Sp. Power }\end{array}$} & \multirow[t]{2}{*}{ Distribution } \\
\hline & & Horizontal & Vertical & & \\
\hline Bosch et al [23] & $\begin{array}{l}\text { 3-Hourly } \\
\sim 50 \mathrm{~km}\end{array}$ & $\begin{array}{l}1 \mathrm{~km} \text { average } \\
\text { matching }\end{array}$ & $\begin{array}{l}\text { Regression } \\
(2,10,50 \mathrm{~m})\end{array}$ & $\begin{array}{c}4.0 \mathrm{MW} \\
100 \mathrm{~m} \\
428 \mathrm{~W} \mathrm{~m}^{-2}\end{array}$ & $\begin{array}{l}6.52 \mathrm{MW} \mathrm{km}^{-2} \text {, } \\
\text { With suitability }\end{array}$ \\
\hline $\begin{array}{l}\text { McKenna } \\
\text { et al. } \\
\text { [24] }\end{array}$ & $\begin{array}{l}\text { Monthly } \\
\sim 80 \mathrm{~km}\end{array}$ & - & $\begin{array}{l}10 \mathrm{~m} \text { projection, } \\
\text { Roughness from } \\
\text { land cover }\end{array}$ & $\begin{array}{c}3.3 \mathrm{MW} \\
98 \mathrm{~m} \\
389 \mathrm{~W} \mathrm{~m}^{-2}\end{array}$ & $\begin{array}{l}13.5 \mathrm{MW} \mathrm{km}^{-2} \text {, } \\
\text { With suitability }\end{array}$ \\
\hline UBA [25] & $\begin{array}{l}\text { Hourly } \\
\sim 80 \mathrm{~km}\end{array}$ & \multicolumn{2}{|c|}{$\begin{array}{l}2.8 \mathrm{~km} \text { distribution } \\
\text { matching at hub height }\end{array}$} & $\begin{array}{c}3.3 \mathrm{MW} \\
120 \mathrm{~m} \\
356 \mathrm{~W} \mathrm{~m}^{-2}\end{array}$ & $\begin{array}{c}\text { Explicit } \\
\text { placements }\end{array}$ \\
\hline JRC [20] & $\begin{array}{l}\text { Hourly } \\
\sim 50 \mathrm{~km}\end{array}$ & $\begin{array}{l}1 \mathrm{~km} \text { dist. } \\
\text { matching }\end{array}$ & $\begin{array}{l}\text { Regression } \\
(10,50 \mathrm{~m})\end{array}$ & Historic & - \\
\hline $\begin{array}{c}\text { Staffel \& } \\
\text { Pfenninger [22] }\end{array}$ & $\begin{array}{l}\text { Hourly } \\
\sim 50 \mathrm{~km}\end{array}$ & Interpolation & $\begin{array}{l}\text { Regression } \\
(2,10,50 \mathrm{~m})\end{array}$ & Historic & - \\
\hline $\begin{array}{c}\text { Zappa \& } \\
\text { Broek [21] }\end{array}$ & $\begin{array}{l}\text { 3-Hourly } \\
\sim 50 \mathrm{~km}\end{array}$ & - & $\begin{array}{c}10 \text { m projection, } \\
\text { Constant } \\
\text { roughness }\end{array}$ & $\begin{array}{c}3.3 \mathrm{MW} \\
125 \mathrm{~m} \\
318 \mathrm{~W} \mathrm{~m}^{-2}\end{array}$ & $\begin{array}{l}5.1 \mathrm{MW} \mathrm{km}^{-2} \text {, } \\
0.06 \text { suitability }\end{array}$ \\
\hline Robinius [19] & $\begin{array}{c}\text { Hourly } \\
\text { Weather station }\end{array}$ & $\begin{array}{r}1 \mathrm{kn} \\
\text { matching }\end{array}$ & $\begin{array}{l}\text { average } \\
\text { t hub height }\end{array}$ & $\begin{array}{c}3.9 \mathrm{MW} \\
140 \mathrm{~m} \\
240 \mathrm{~W} \mathrm{~m}^{-2}\end{array}$ & $\begin{array}{c}\text { Explicit } \\
\text { placements }\end{array}$ \\
\hline
\end{tabular}

sub-optimal exploitation of available areas.

The potential of wind energy in Europe is a commonly discussed topic in the literature which has significant impact on the design of future energy systems, although there is no single study which combines the best qualities of previous approaches consistently across the European context. Therefore, this report seeks to fill this void by providing a fully transparent, reproducible, and up-to-date estimation of the future potential of onshore wind energy in Europe. In order to accomplish this, the following topics will be addressed: First, three largely-independent sub-methodologies will be discussed which assess: design and distribution of future-oriented turbines, turbine simulation, and cost estimation. Following this, a discussion on the validity of the simulation and design approaches is given. At last, the result of combining the sub-modules in an overall evaluation is presented; thereby giving the total potential of wind energy capacity and electricity generation of the European countries as well as detailing the impact of imposing an economic limitation on these potentials.

\section{Methodology}

The methodology used for this analysis was envisioned to expand on the approach of Robinius [19], and aims to determine the potential for onshore wind energy capacity and generation for any arbitrarily defined region. By estimating average generation costs of single turbine locations, this approach allows for the further investigation of these potentials in the context of an economic restriction. Figure 1 summarizes the procedures used, which will be described in detail in the following sections. The general procedure begins by selecting a region that is to be investigated. This is not limited to any geographic scope, although for the analysis conducted here the European countries are chosen. In the first stage the unsuitable areas for onshore wind turbines are excluded. Using a placement 
algorithm, the maximal number of turbine installation sites are identified, and then a design scheme suggests locationspecific and future-oriented characteristics. Afterwards, simulation determines hourly generation over a 37 year time span, leading into an economic evaluation of each location. At this point, total technical potentials for capacity, generation, and LCOE are available, after which turbines are filtered by LCOE revealing economically constrained potentials.

Figure 1: Overview of procedure employed in this analysis. Order of operations is shown by the downward connections between items, while indentation indicates logical dependence. Items with an outward pointing arrow represent the primary results of this analysis. Images on the right provide an exemplary depiction of several key stages.

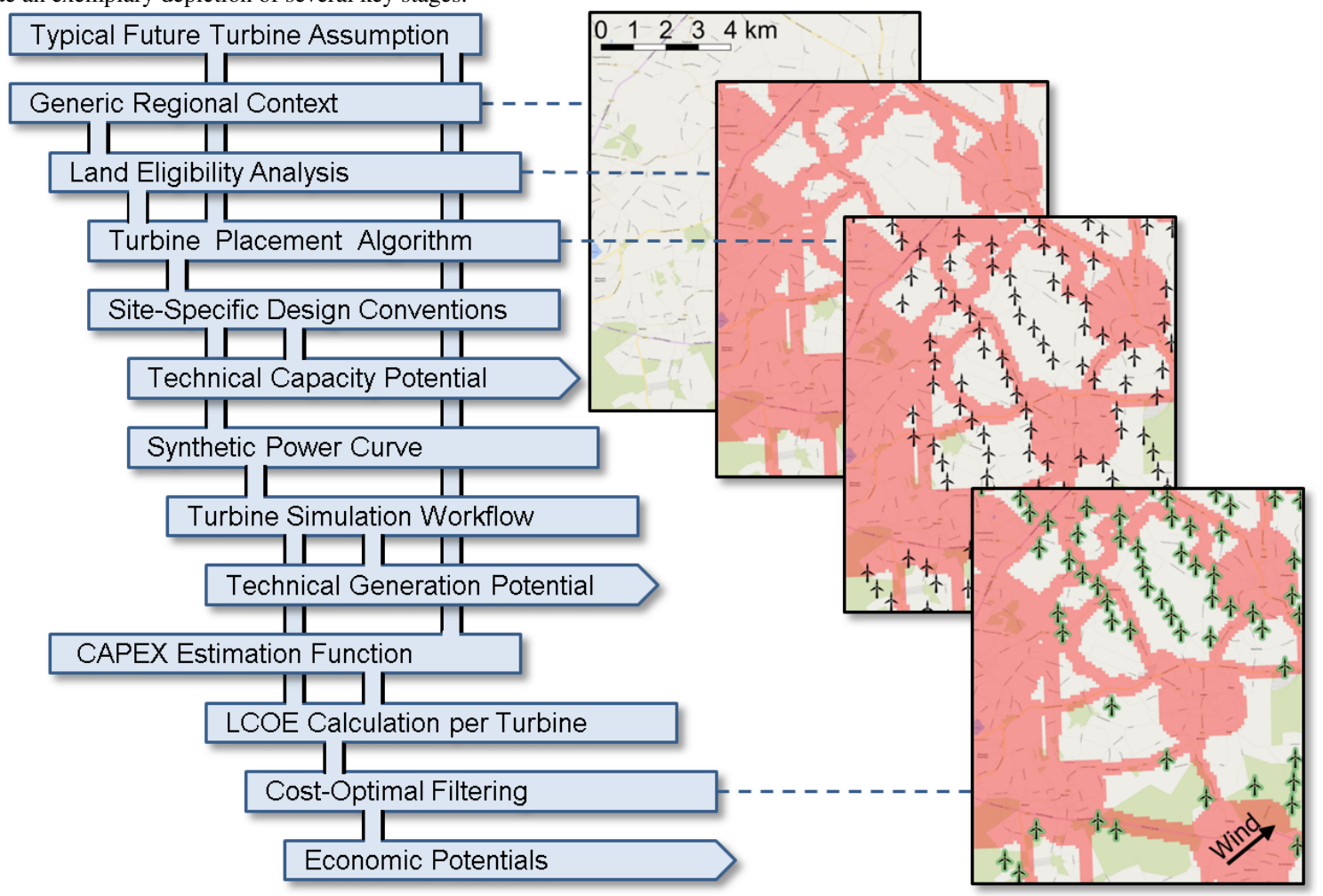

\subsection{Turbine Distribution And Design}

\subsubsection{Land Eligibility and Placement}

To ensure that wind turbines are not placed in those areas which should be excluded, a uniform land eligibility scenario is taken into account. Since the land eligibility analysis used here is discussed in detail in a previous work [28], this issue is only summarized. The GLAES [29, 30] model was used to perform this analysis, as it was specially designed for the purpose of land eligibility analyses, and 30 constraints were imposed across the European landscape. As discussed in the referenced work, after applying the turbine designing and placement scheme across the European landscape, a total of 1.35 million $\mathrm{km}^{2}$ is found to be available across Europe, constituting $27.3 \%$ of the available land [28].

By consulting the availability matrix ${ }^{2}$ resulting from the land eligibility analysis, the placement algorithm finds the coordinates of potential placements such that the locations are not in the immediate vicinity of neighboring turbines. Based on the suggestions of Jäger et al. [31], Emami and Noghreh [32], and McKenna et al. [33], the exclusive vicinity of each turbine is defined as the area of an ellipse with major and minor axes equaling 8 and 4 times rotor

\footnotetext{
${ }^{2}$ true or false values on a $100 \mathrm{~m}$ by $100 \mathrm{~m}$ grid
} 
diameter of each turbine, oriented with the major axis parallel to the predominant wind direction ${ }^{3}$. The placement algorithm begins at the north-westernmost pixel and scans each row of the availability matrix recording which pixels are available. Then, beginning at the first identified available pixel, the algorithm scans the pixel from left-to-right and top-down looking for the first suitable location which is not in the vicinity of previously located placements. This procedure is continued until all available pixels have been considered, thereby finding a representative set of the maximal number of potential wind turbine locations across Europe.

\subsubsection{Turbine Design}

As the International Electrotechnical Commission's (IEC) suggests, wind turbines are currently categorized into various classes according to the expected time-averaged wind speed as well as the degree of turbulence [34]. Turbine class comments on the mechanical stresses that the turbine is engineered to withstand long enough that it can be safely operated over a 20 year lifespan. In order to account for technological advancements, a more detailed analysis would project turbine designs within each of these categories to a future context. On average, however, historical design trends in Europe [35] reveal that from 2007 until 2016 there has been a steady increase in turbine capacity, hub height, and rotor diameter, in addition to a steady decrease in turbine specific power. When linearly fitted, the 2016 average hub height of $100 \mathrm{~m}$ appears to be growing at a rate of $2 \mathrm{~kW} \mathrm{a}^{-1}$, the average rotor diameter of $110 \mathrm{~m}$ appears to be growing at $2.5 \mathrm{~m} \mathrm{a}^{-1}$, the average capacity of $2.6 \mathrm{MW}$ is growing at $70 \mathrm{~kW} \mathrm{a}^{-1}$, and finally the average specific power of $320 \mathrm{~W} \mathrm{~m}^{-2}$ is decreasing at a rate of $8 \mathrm{~W} \mathrm{~m}^{-2} \mathrm{a}^{-1}$. Of course, these trends depend on the country in question and certainly cannot be expected to continue indefinitely. Therefore, the baseline turbine summarized in Table 2 is chosen for use in the 2050 context evaluated for this analysis as it's characteristics represent conservative estimates in comparison to the historical trends. Furthermore, these turbine characteristics align with a projection which is deemed 'likely' by the IEA [36] and are well within the range of typical future turbine designs estimated by industry experts [37]. Moreover, these characteristics correspond to the currently available Vestas V136, 4.2 MW, wind turbine [38]; meaning this is a proven turbine configuration which can only be improved upon in the coming decades.

Table 2: Summary of assumptions for the baseline turbine. All other turbines which are simulated will have qualities which deviate from the baseline values.

\begin{tabular}{ll}
\hline Quality & Value \\
\hline Design: & \\
Hub Height & $120 \mathrm{~m}$ \\
Rotor Diameter & $136 \mathrm{~m}$ \\
Capacity & $4200 \mathrm{~kW}$ \\
Specific Power & $289 \mathrm{~W} \mathrm{~m}^{-2}$ \\
\hline Economic: & \\
Capital Cost (CapEx) & $1100 € \mathrm{~kW}^{-1}$ \\
Annual Operating Cost & $2 \%-$ of - CapEx \\
Economic Lifetime & 20 years \\
Interest Rate & $8 \%$ \\
\hline
\end{tabular}

To incorporate spatial sensitivity to turbine design, the assumption is made that relative differences in turbine designs between sites with high versus low average wind speeds would remain similar to what is observed today. Therefore, the World Wind Farms Database [39] from The Wind Power is consulted to determine fitting functions of turbine hub height and specific power versus the installation site's average $100 \mathrm{~m}$ wind speed for wind farms installed in Europe between 2013 and 2017. In each case, average wind speed is found by extracting the relevant locations from the GWA [40] dataset created by the Technical University of Denmark, which provides time-averaged wind speeds at 50,100 , and $200 \mathrm{~m}$ altitude for each $1 \mathrm{~km}$ by $11 \mathrm{~km}$ area across the globe. The resulting fitting functions are then scaled such that the baseline turbine's characteristics are returned when an site average wind speed of $6.54 \mathrm{~m} / \mathrm{s}^{4}$ is

\footnotetext{
${ }^{3}$ Computed by extracting $50 \mathrm{~m}$ wind speeds from MERRA

${ }^{4}$ Determined from our own calculations from the farms found in the World Wind Farm Database and their coinciding $100 \mathrm{~m}$ wind speeds from the GWA
} 
specified. These final conventions, given in Equations 1 and 2, are furthermore adjusted such that the hub height is not allowed to fall below $88 \mathrm{~m}$, such that a minimal ground-to-tip height of $20 \mathrm{~m}$ is maintained. Moreover, in order to allow for a constant distance calculation to be applied within the turbine placement algorithm, rotor diameter is held constant at the baseline turbine's value of $136 \mathrm{~m}$. Finally, locations where average wind speed exceeds $9.5 \mathrm{~m} \mathrm{~s}^{-1}$ are not considered as there are no large-scale wind parks installed beyond this value. Figure 2 a displays the result of applying these design criteria at wind speeds between 4 and $9.5 \mathrm{~m} \mathrm{~s}^{-1}$, and furthermore shows the distribution of average wind speeds across Europe found within the GWA. Figure 3 displays the final distribution of turbine design employed across Europe, where a $5 \mathrm{~km}$ averaging kernel is additionally applied to the GWA wind speeds in order to suppress design fluctuations over short distances.

$$
\begin{aligned}
& \text { hub height }=1.240910 \cdot \exp (-0.849766 \cdot \ln (\text { wind speed })+6.187994) \\
& \text { specific power }=0.900260 \cdot \exp (0.537690 \cdot \ln (\text { wind speed })+4.749177)
\end{aligned}
$$

Figure 2: On the left, turbine design conventions in response to average $100 \mathrm{~m}$ wind speed at the installation location. For reference, the relative distribution of observed wind speeds is shown in the background [40]. On the right, exemplary synthetic power curves are generated for 3, 4.2, and $5 \mathrm{MW}$ turbines; each with a rotor diameter of $136 \mathrm{~m}$ and a cut-out wind speed of $25 \mathrm{~m} \mathrm{~s}^{-1}$.

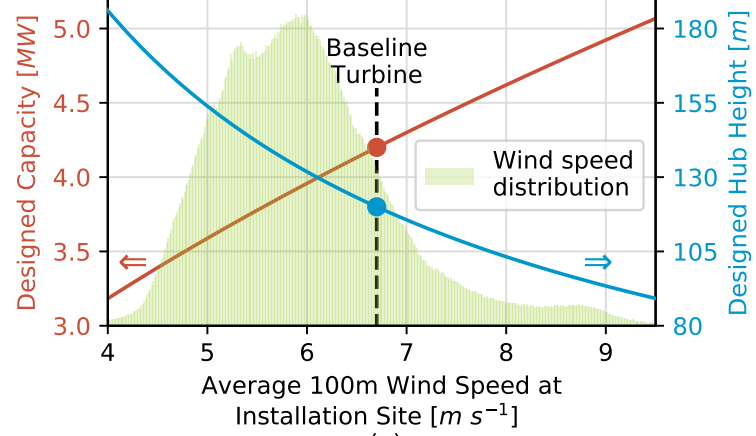

(a)

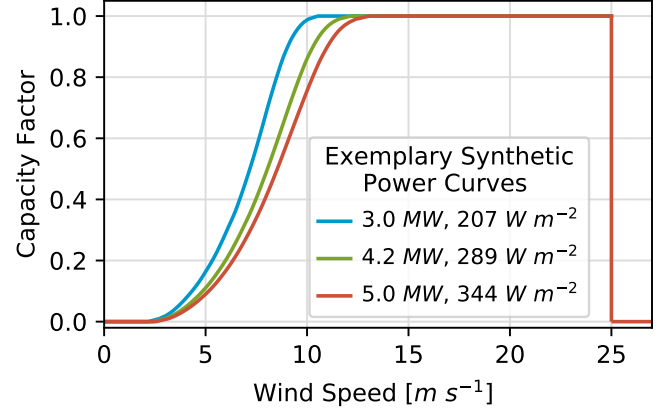

(b)

\subsubsection{Synthetic Power Curve}

Current trends show that both rotor diameter and capacity are increasing on average, however increases in rotor diameter are out pacing increases in capacity resulting in the observed decreasing trend in specific power [35]. This, along with the increasing hub heights, are primarily responsible for future increasing full load hours (FLH) [7], and is taken into account in this analysis via the development of a method to generate synthetic power curves as a function of specific power. To accomplish this, approximately 130 power curves of three-bladed, horizontal-axis, upwind, pitch-regulated, onshore wind turbines larger than $1 \mathrm{MW}$ were selected from the Power Curve Database [41] from The Wind Power. The highest specific power amongst these turbines is from the Enercon E-126 7580 at 7.5 MW capacity and $127 \mathrm{~m}$ rotor diameter, resulting in a specific power of $592 \mathrm{~W} \mathrm{~m}^{-2}$, while the smallest value of $199 \mathrm{~W} \mathrm{~m}$ corresponds to the Siemens SWT-3.15-142 turbine with a 3.15 MW capacity and a $142 \mathrm{~m}$ rotor diameter. Considering the transition between the cut-in and rated wind speed within the provided real power curves, then, for each $1 \%$ increment in capacity factor (CF), fitting functions were developed that map a given specific power to the wind speed at which that $\mathrm{CF}$ is reached. Assuming the exclusive installation of upwind and pitch regulated wind turbines [7], a $\mathrm{CF}$ of 1 is maintained after the rated power wind speed until decreasing to zero after the cutout wind speed; which for this analysis is always assumed to be $25 \mathrm{~m} \mathrm{~s}^{-1}$. The resulting fitted constants, equations, and details of their use are provided in appendix Appendix A. Figure $2 \mathrm{~b}$ provides a sample output of this procedure, where generated power curves are created for turbine capacities of 5, 4.2, and $3 \mathrm{MW}$, where a $136 \mathrm{~m}$ rotor diameter is assumed in all cases. The full development procedure of the synthetic turbine method is discussed in Appendix Appendix A. 
Figure 3: Turbine design conventions applied to Europe, where $100 \mathrm{~m}$ average site wind speeds are supplied by GWA. A $5 \mathrm{~km}$ averaging kernel is applied to the GWA wind speeds in order to suppress design fluctuations over short distances.

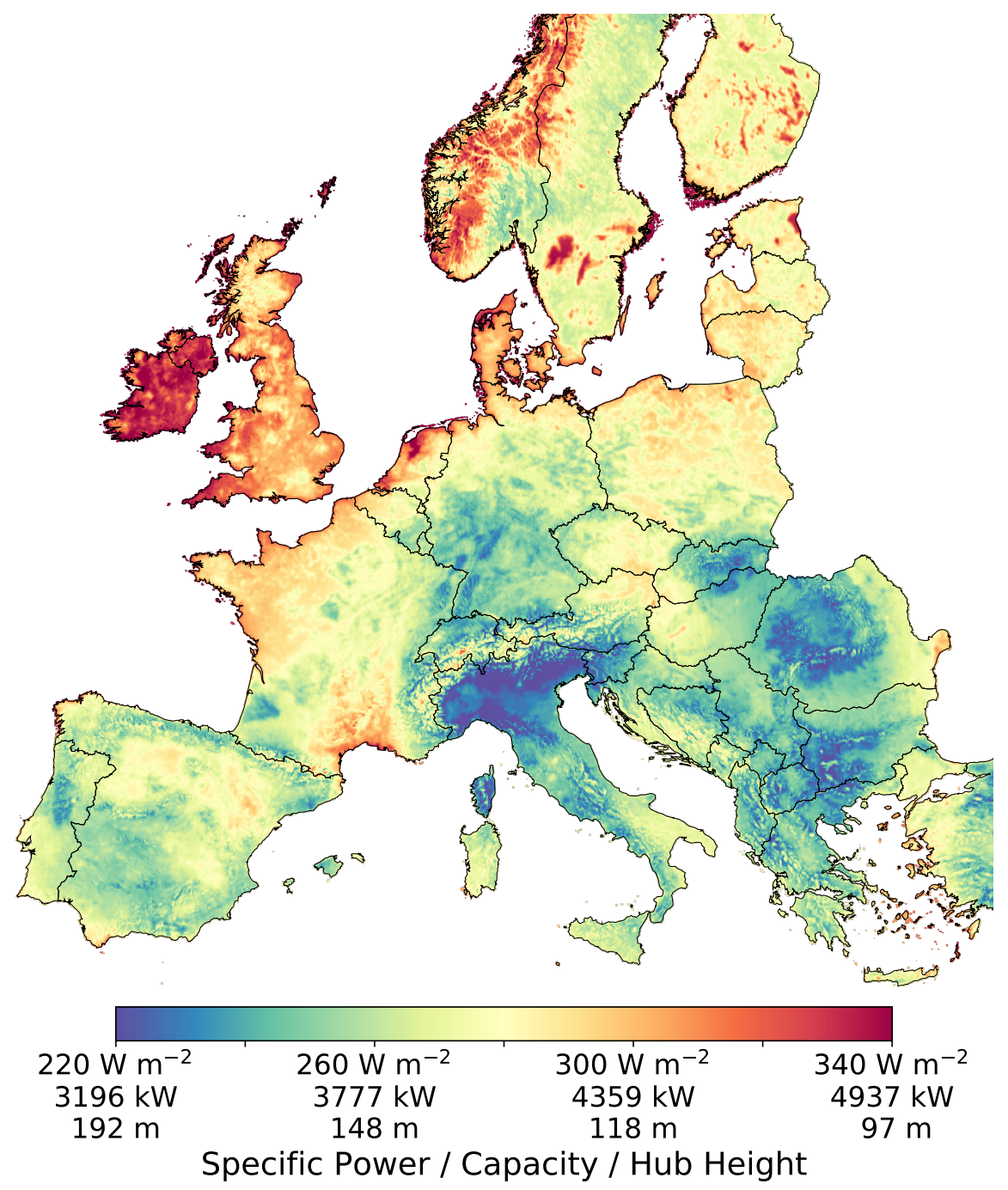

\subsection{Turbine Simulation}

Generation simulation at any location is accomplished in four stages: reading raw time series data generated from a global climate model, by adjusting these values to a local context, by projecting these winds speeds to turbine hub height and performing air density correction, and finally applying losses. The MERRA dataset is used to provide hourly $50 \mathrm{~m}$ wind speed, as well as surface temperature and pressure time series data between 1980 until, at the time of this writing, the end of 2017. This time series data is available at each point within a $0.5^{\circ}$ latitude by $0.625^{\circ}$ longitude spatial grid; which in the context of central Europe translates to a distance of $\sim 50 \mathrm{~km}$ between grid points depending on location. For each simulation point, the raw time series data from the nearest MERRA grid point is extracted and processed.

\subsubsection{Long-Run Average Adjustment}

Due to the coarse resolution of MERRA, spatial adjustment of the MERRA wind speed time-series to the expected time-averaged provided by GWA is required in order to better represent local wind effects. This is performed by computing a scaling factor at each location, which is then used to adjust the time series wind speeds as shown in 
Equation 3. Where $v$ indicates the local-adjusted wind speed, $v_{M E R R A}$ represents hourly wind speeds extracted from MERRA, $v_{G W A, 50 m}$ is the average wind speed at $50 \mathrm{~m}$ given by GWA, and $v_{M E R R A, a v g}$ is the average of MERRA wind speeds in the corresponding grid cell across all available years.

$$
v=v_{M E R R A} \cdot \frac{v_{G W A, 50 m}}{v_{M E R R A, a v g}}
$$

\subsubsection{Log Profile Projection}

Despite being adjusted to a local scale, wind speeds are still in reference to a $50 \mathrm{~m}$ altitude that needs to be adjusted to turbine hub height. For this, the logarithmic wind profile is used while assuming zero displacement height and neutral stability conditions. Equation 4 displays how the known wind speeds at $50 \mathrm{~m}$ altitude are used to project to turbine hub height; where wind speed $(v)$ and altitude $(h)$ are represented as $v$ and $h$, respectively, and the shape of the logarithmic profile is determined by the roughness length, $z$.

$$
v_{h u b}=v_{50 m} \cdot \frac{\ln \left(h_{h u b} / z\right)}{\ln (50 / z)}
$$

The Corine Land Cover (CLC) dataset is used to determine land cover categories as it provides a consistent overview of the European environment; in which 44 different land cover categories are distinguished with a spatial resolution of $100 \mathrm{~m}$. After extracting the CLC category for each simulation location, roughness lengths are then determined according to the suggestions by Silva et al. [42].

\subsubsection{Air Density Correction}

As detailed by IEC 61400-12 [43], air density correction is considered to account for the fact that wind turbine power curves are generally given in reference to standard air density $\left(\rho_{s t d}\right)$ of $1.225 \mathrm{~kg} \mathrm{~m}^{-2}$. To make this correction,

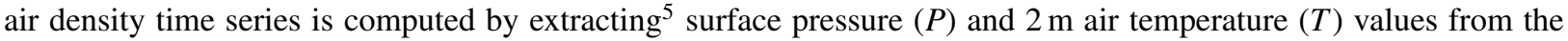
same MERRA dataset which provided the original wind speed values. In doing so, the assumptions of an ideal gas and molar mass for air $\left(M_{a}\right)$ of $0.028964 \mathrm{~kg} \mathrm{~mol}^{-1}$ are used. Afterwards, this surface density is projected to turbine hub height using the Barometric equation. Finally, as suggested in IEC 61400-12, wind speed correction factors are computed to a standard air density referenced wind speed $\left(v_{s t d}\right)$ such that the kinetic energy contained in the wind is maintained. Equation 5 contains these steps represented as a single equation; where $g$ represents gravitational acceleration and $R$ is the universal gas constant.

$$
v_{s t d}(t)=v(t) \cdot\left[\frac{1}{\rho_{s t d}} \cdot \frac{P(t) M_{a}}{R T(t)} \cdot \exp \left(\frac{-g M_{a} h_{h u b}}{R T(t)}\right)\right]^{1 / 3}
$$

\subsubsection{Power Curve Convolution}

If a turbine's generation exactly followed its power curve, then once wind speeds were known, the turbine's generation could be found simply by identifying the corresponding power output on the power curve. In reality, wind turbine performance is in fact a stochastic response to wind speed, and so a turbine's generation can only be summarily estimated by the power curve. The reasons for this are numerous; including reduced aerodynamic efficiency caused by turbulence in the wind, large wind speed gradients across the rotor blades, wind speed fluctuation exceeding the turbine's response time, and especially the source of wind speed values themselves. Therefore in order to translate wind speed values to turbine power generation values, interpolation is performed on a convoluted power curve.

To account for these stochastic effects, a spread of turbine responses around the idealized wind speed are convoluted into a given power curve. For this purpose, the procedure described by Staffel and Pfenninger [22] is employed, wherein the power curve is convolved by a Gaussian kernel defined by a wind speed dependent standard deviation. Equation 6 details how the width of the wind speed dependent standard deviation is determined, where, for this analysis, a scaling factor $\left(\sigma_{\text {scale }}\right)$ of 0.06 and a base value $\left(\sigma_{\text {base }}\right)$ of 0.1 are used. Representation of a power curve before

${ }^{5}$ Using bilinear interpolation between grid points 
Figure 4: The effect of convolution is shown for the synthetic power curve of the baseline turbine. The blue curve shows the unadjusted power curve, the green trend represents convolution effects of the parameters chosen for this analysis, and the red curve shows the effect of stronger convolution parameters.

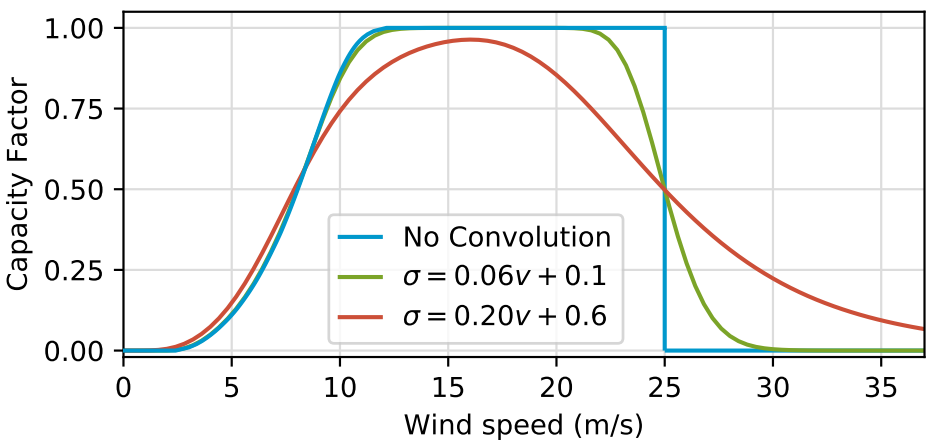

an after convolution with exemplary factors can be seen in Figure 4. Equation 7 displays the full convolution computation which can be applied to any given power curve; where $v$ indicates a wind speed, and $P C$ indicates a functional representation of a power curve.

$$
\begin{gathered}
\sigma(v)=\sigma_{\text {scale }} \cdot v+\sigma_{\text {base }} \\
P C_{\text {conv }}(v)=\int_{0}^{\infty} \frac{1}{\sqrt{2 \pi \cdot \sigma(v)}} \cdot \exp \left(\frac{\left(v^{\prime}-v\right)^{2}}{2 \sigma(v)}\right) \cdot P C\left(v^{\prime}\right) d v^{\prime}
\end{gathered}
$$

\subsubsection{Low-Generation Correction}

Once the power curve is convoluted, the power output from a wind turbine is estimated by identifying the generation expected by the new power curve in response to the input wind speeds. Nevertheless, the theoretical power output of a wind turbine or a wind farm is different than the actual value because of losses such as availability of wind turbines, electrical inefficiencies during transportation and conversion, wake effects and mechanical degradation. Quantifying each loss in detail with an accurate value is highly speculative, yet overall loss factors used in literature often vary between 5 to $20 \%$ [44, 22, 45]. However, as previously discussed, convolution of the power curve already accounts for many stochastic effects which contribute to these losses, so a holistic loss factor is not applied in this work flow. Nevertheless, noticeable over-prediction of the power compared to measured data was still observed mainly at low generation times and so a capacity-factor-dependent correction factor calculated using Equation 8 is used to predominantly suppress the low generation periods. For this analysis, values of 1 and 5 are used for the base (b) and sharpness $(s)$, respectively.

$$
\text { correction factor }=(b-\exp (-s \cdot \text { capacity factor }))
$$

\subsection{Cost Modeling and Turbine Selection}

In the context of 2050 and for the baseline turbine given in Table 2, an average cost of $1100 € \mathrm{~kW}^{-1}$ is assumed $[13,16,15]$. However, as this cost is only meant to represent the typical cost of wind turbines in 2050 , a fluctuation around this cost as a function of turbine design is expected. Therefore, a cost model which is a function of turbine capacity, hub height, and rotor diameter and developed by the National Renewable Energy Laboratory (NREL) [46, 47] is employed to provide cost deviance around the baseline assumptions given in Table 2. This is accomplished by scaling the outputs of the NREL cost model such that, when the characteristics of the baseline turbine are given, the $1100 € \mathrm{~kW}^{-1}$ value is recovered. Equation 9 displays these scaling values, where $c$ is a turbine's capacity, $r d$ is rotor diameter, and $h h$ is hub height. Finally, as suggested by NREL's latest review of onshore turbine costs [48], the individual TCC and BOS scalings values are set such that the TCC of the baseline turbine amounts to $67.3 \%$ of the 
total cost, the BOS amounts to to $22.9 \%$ of the total cost, and an additional $9.7 \%$ is added for financial costs. When applied to the turbine design conventions of Equations 1 and 2, the use of the normalized NREL cost model results in the nonlinear cost estimation trend as a function of installation site wind speed that is shown in Figure 5.

$$
\operatorname{cost}=1.018841 \cdot \operatorname{nrel}_{T C C}(c, r d, h h)+0.714326 \cdot \operatorname{nrel}_{B O S}(c, r d, h h)
$$

Figure 5: Estimated turbine cost as a function of the installation site's average wind speed. Design conventions are described in Section 2.2, and more specifically by Equations 1 and 2.

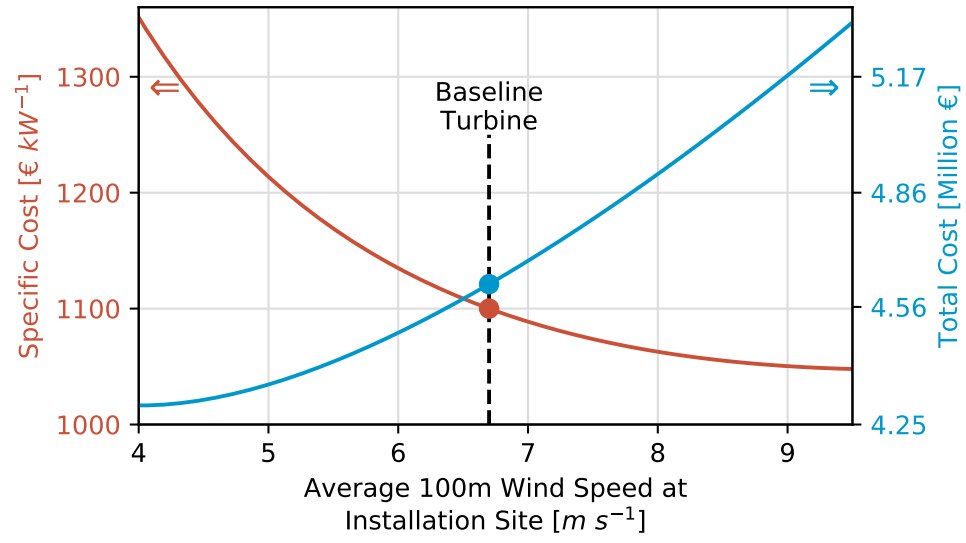

\subsubsection{LCOE Computation}

LCOE is next computed for each potential turbine location using average FLH and total system cost alongside the other economic parameters in Table 2. In line with the results shown by Perez [49], a downtime factor of $5 \%$ is applied to the FLH. Equation 10 is then used to compute LCOE, where capex refers to the total capital cost of the turbine in question, gen is the average generation per year including downtime, $r$ is the interest rate, $n$ is the economic lifetime, and finally sp. opex is the specific operating expenditures given as a factor of the capex.

$$
L C O E=\frac{\text { capex }}{\text { gen }} \cdot\left(\frac{r}{1-(1+r)^{-n}}+\text { sp. opex }\right)
$$

\section{Validation}

\subsection{Hourly Comparison}

Hourly comparisons are made against two wind parks; Princess Alexia in the Netherlands and La Haute Borne in western France. The Princess Alexia wind park consists of 36 Senvion 3.4M104 wind turbines at a hub height of $98 \mathrm{~m}$. Each of these turbines were located with precise latitude and longitude coordinates via manually reviewing satellite imagery data. Generation data for this park was retrieved for 2015 and 2016 from the European Energy Exchange (EEX)[50]. The La Haute wind park consists of 4 Senvion MM82 wind turbines at a hub height of $80 \mathrm{~m}$. Detailed location and measurement data for the La Haute park's wind turbines is provided through by the ENGIE Group [51, 52] and includes sub hourly production data between 2009 until 2017 for each turbine, in addition to measured wind speed, wind direction, temperature, grid voltage, and other parameters. For the sake of this analysis, only aggregated hourly generation data across the whole park for 2015 and 2016 is considered to match the availability of the Princess Alexia data. Additionally, only hours in which measurements were reported for all four turbines in the park were considered in the comparison; resulting in slightly below 13,000 values to consider.

Figure 6 provides a sample of the outcome of these comparisons and Table 3 provides statistical summaries. The model does an acceptable job at recreating the measured generation from these parks, as the range of generation and significant fluctuations are recreated well. Princess Alexia estimations, shown in blue, however, appear to fit much 
Figure 6: Visual comparison of hourly generation values against the Princess Alexia and La Haute wind parks. A large total percent error was found when applying the proposed method to the La Haute park (shown in red), however when correcting the average wind speed to the actually observed value (shown in green), the overall error was reduced considerably.
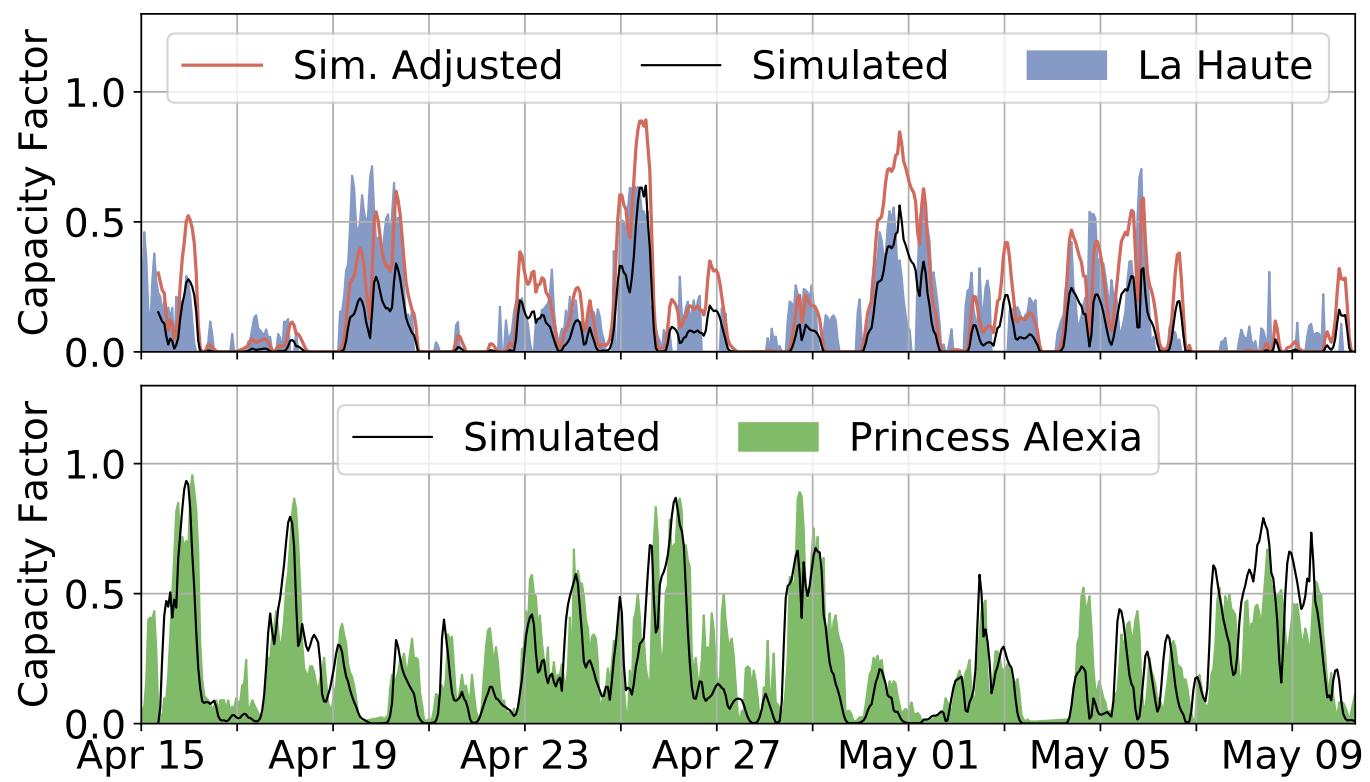

better than the La Haute simulations, shown in red. Indeed, when viewed across longer time frames the model is shown to slightly under predict generation from Princess Alexia by $5.05 \%$, while it under predicts generation from La Haute $37.65 \%$. The large discrepancy for La Haute is expected to be an outcome of the long-run average adjustment procedure. Due to the availability of wind speed data for La Haute, this hypothesis was directly tested by using the actual observed time-averaged wind speeds instead of GWA for spatial adjustment resulting in the green line in Figure 6. After making this change, total percent error was reduced to an over prediction of $3.77 \%$. Therefore under and over predictions of the model are highly dependent on the downscaling accuracy of GWA. A strong correlation is observed in both cases, however the normalized root mean squared error (RMSE) shows that the error in hourly fluctuations can be quite high; reaching, for example, $48 \%$ of the average generation value for Princess Alexia. This discrepancy is thought to be due a combination of the inability of the MERRA dataset to recreate local context wind fluctuations as well as by land cover changes, and therefore roughness length changes, since the publication of CLC.

Table 3: Summary of various statistical measures when comparing simulated and measured generation data from the La Haute and Princess Alexia wind parks

\begin{tabular}{rccc}
\hline Measure & Princess Alexia & La Haute & La Haute - Corrected \\
\hline Absolute Error [\%] & -5.05 & -37.65 & 3.77 \\
Normalized RMSE [\%] & 47.91 & 63.40 & 61.23 \\
Correlation & 0.88 & 0.80 & 0.81 \\
\hline
\end{tabular}

\subsection{Regional Comparison}

Monthly generation estimations are compared to turbines spread across Denmark between 2002 and 2011 provided in the "Master Data Register of Wind Turbines" from the Danish Energy Agency [53]. This dataset includes capacity, hub height, rotor diameter, installation date, and location of over 6,100 wind turbines installed in Denmark; of which only onshore turbines with greater than $2000 \mathrm{~kW}$ capacity and a known power curve are considered for comparison. After filtering, 86 known turbines remain spanning capacities from 2 to $3.6 \mathrm{MW}$, rotor diameters from 73 to $120 \mathrm{~m}$, 
hub heights from 68 to $94 \mathrm{~m}$, and specific powers from 312 to $473 \mathrm{~W} \mathrm{~m}^{-2}$. The percent error of estimated monthly generation values compared against the reported measurements is found, and the result is shown in Figure 7.

Figure 7: Monthly validation against 86 Turbines in Denmark, simulated from 2002 until the end of 2011

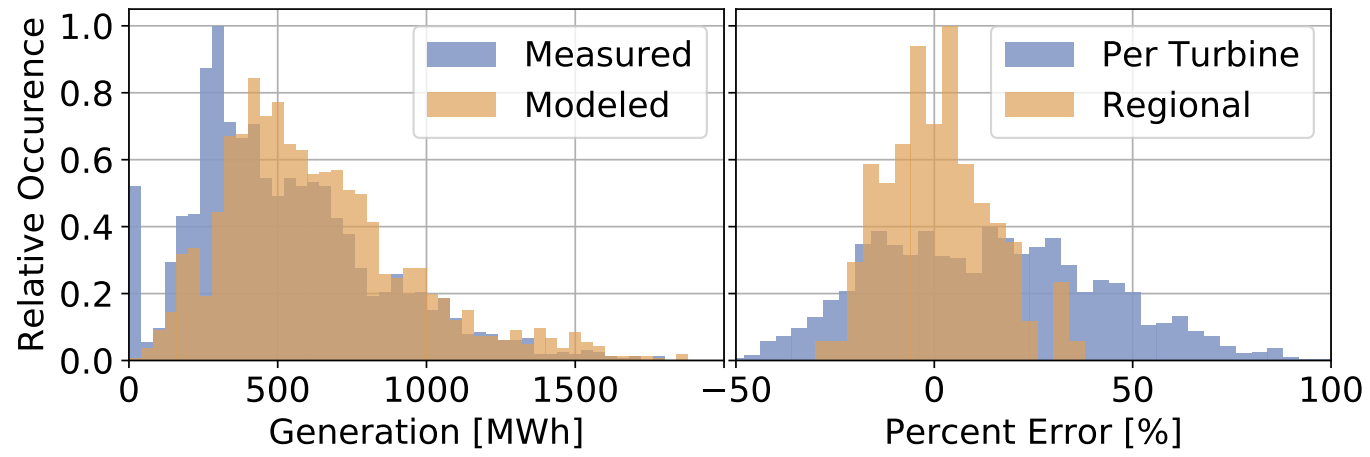

When comparing the generation histograms shown to the left of Figure 7, a transition is seen at 300 MWh below which a smaller population of modeled observations is seen and above which an over population is found. This over prediction is also seen in the percent error per turbine histogram, shown in blue to the right of Figure 7, where the most likely observations are found between -20 and $30 \%$, with a over estimating tail extending beyond $80 \%$. These measurement values are certain to include dynamics which cannot be predicted in the current state of this model, such as downtime and curtailment, although unlike the hourly comparisons, missing or otherwise clearly erroneous data cannot be easily removed as only monthly sums are known. As a result an overestimation is expected, but to what degree is uncertain without detailed knowledge of the data gathering and processing procedures used by the Danish Energy Agency. Therefore, these results are not conclusive of an over prediction of the proposed model in Denmark. Nevertheless, when taking a regional perspective, it seen that over and under predictions for individual turbines tend to balance each other. This is shown by the orange distribution on the right of Figure 7, where generation is aggregated for all turbines within each reported month and the resulting distribution is nearly symmetrically centered around $0 \%$ error with tails extending to $\pm 30 \%$. As a result of this observation, in addition to the agreements observed for the hourly validations, it is concluded that the simulation model behaves reliably well for estimating turbine generation.

\subsection{Design Context Comparison}

Figure 8 presents the outcome of comparing different design contexts evaluated across Germany. The solid lines represent the average FLH value for a homogeneous turbine design used for all available locations in Germany, as identified by the placement algorithm, while the dashed lines represent the best $40 \%$ of these locations in terms of FLH. These trends clearly show how the expected FLH is sensitive to turbine design; that when the typical hub height of turbines increases, or when the typical specific power decreases, higher FLH values should be observed. The other points found in Figure 8 show the average FLH reported by various sources in a variety of design contexts. Values taken from the German Environmental Agency (UBA) [25], McKenna et al. [24], European Environmental Agency (EEA) [54], and Robinius [19] are all meant to represent the average German FLH in a future context for all potential turbines. When considering comparable contexts, estimations of the model shows close agreement with the EEA value, is significantly more conservative than the values given by McKenna and by UBA, and is in the same range as the value predicted by Robinius [19]. The square points show the average FLH of real grid connected turbines in Germany as reported by the International Energy Agency (IEA) [35] between 2009 and 2017. Although the IEA values are subject to the inter-annual variability, they clearly show the progression of increasing FLH resulting from improved turbine design which is reflected by the model used in this analysis. Furthermore, the FLH values reported by IEA represent the average FLH of installed turbines, which will naturally exclude poor performing locations, so are more comparable to the dashed design trends. These trend lines are found to be in the same range as the values reported by IEA. From these comparisons, it appears evident that the model is shown to predict similar average FLH values across Germany as both estimated and reported values when similar turbine designs are used. Moreover, while the 
Figure 8: Average German FLH estimated with the model compared to similar estimations and historical values.

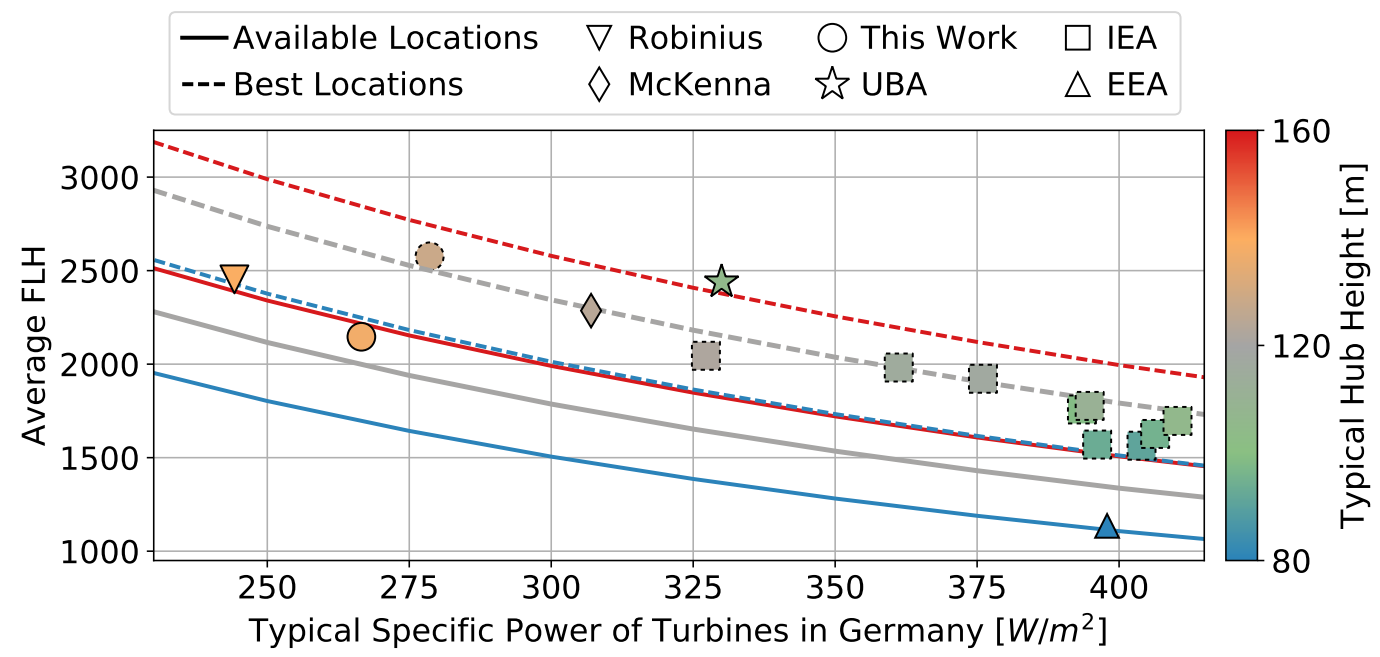

progressive turbine design scenario investigated here will result in significantly higher FLH values compared to these other studies, this discrepancy appears to be well in line with a reasonable trend of improving turbine performance.

\section{Results}

In total, 4,130,046 potential locations are identified across Europe, corresponding to $16.1 \mathrm{TW}$ of installable capacity. However, a significant portion of these placements are found within Turkey which does not include its protected area designations within the World Database on Protected Areas (WDPA) [55]. In order to avoid providing biased results Turkey is from hereon excluded, after which a total capacity of $13.4 \mathrm{TW}$ and annual generation of $34.3 \mathrm{PWh}$ remains. Corresponding to $2560 \mathrm{FLH}$ on average, this estimate is far below the average of 3942 FLH predicted for 2050 by the JRC [16]; although the JRC value is likely given in reference to all operating turbines, as opposed to all available. As technical potential, Bosch et al. [23] predict 14.8 PWh generation from 7.8 TW of capacity for the EU28, the IEA estimated 11.5 PWh [56], Mckenna et al. [24] estimated 14.6 PWh, while Zappa and Broek [21] suggest a total capacity potential of $543 \mathrm{GW}$. Of these previous authors, Bosch et al., IEA, and Mckenna et al. used similar land eligibility to that used for this work [30], although Zappa and Broek have employed a highly restricting scenario in which turbines can only be built on agricultural areas and grasslands.

When the simulation scheme is applied to each of these locations, distribution of the resulting average FLHs across Europe are shown in Figure 9. It is clear that Ireland is distinguishable with many well-performing turbine locations; the majority of which exceeding 3800 FLH. The United Kingdom and Denmark both also poss a majority of strong turbine locations; predominantly ranging between 3400 and 4000 FLH. For the Netherlands, Belgium, and Germany strong locations with FLHs around 3000 are found more frequently in proximity to the coast. France has strong locations in the south near to the Mediterranean coast, with FLHs reaching 4000 FLH, and a much larger region can be seen in the North with FLHs around 3000. Many inland locations also show high FLHs, such as North-Eastern Spain, central Poland, and Eastern Austria. A variety of FLHs are seen in the Nordic countries, ranging from less than 2000 to above 4000 FLH. Figure 9 is visualized with an averaging kernel so that trends can be more clearly seen, however in doing so it does not reveal outliers with extremely high or extremely low FLH's which are found in all countries. The maximum FLH is found in Northern Norway with $6033 \mathrm{FLH}$, although this is extremely uncommon since $99 \%$ of locations are found below 4278 FLH. Therefore this outcome is most likely a result of numerical fluctuations in GWA estimations as opposed to a physical reality. Nevertheless, JRC[16] claims that a maximum of 5694 FLH will be observed in Europe in 2050, which represents only a 5.9\% discrepancy.

Figure 10 displays the resulting LCOEs. Unsurprisingly, locations with high average FLH often correlate to low LCOEs, since the specific cost of the turbines at these locations are cheaper owing to their higher capacity and lower 


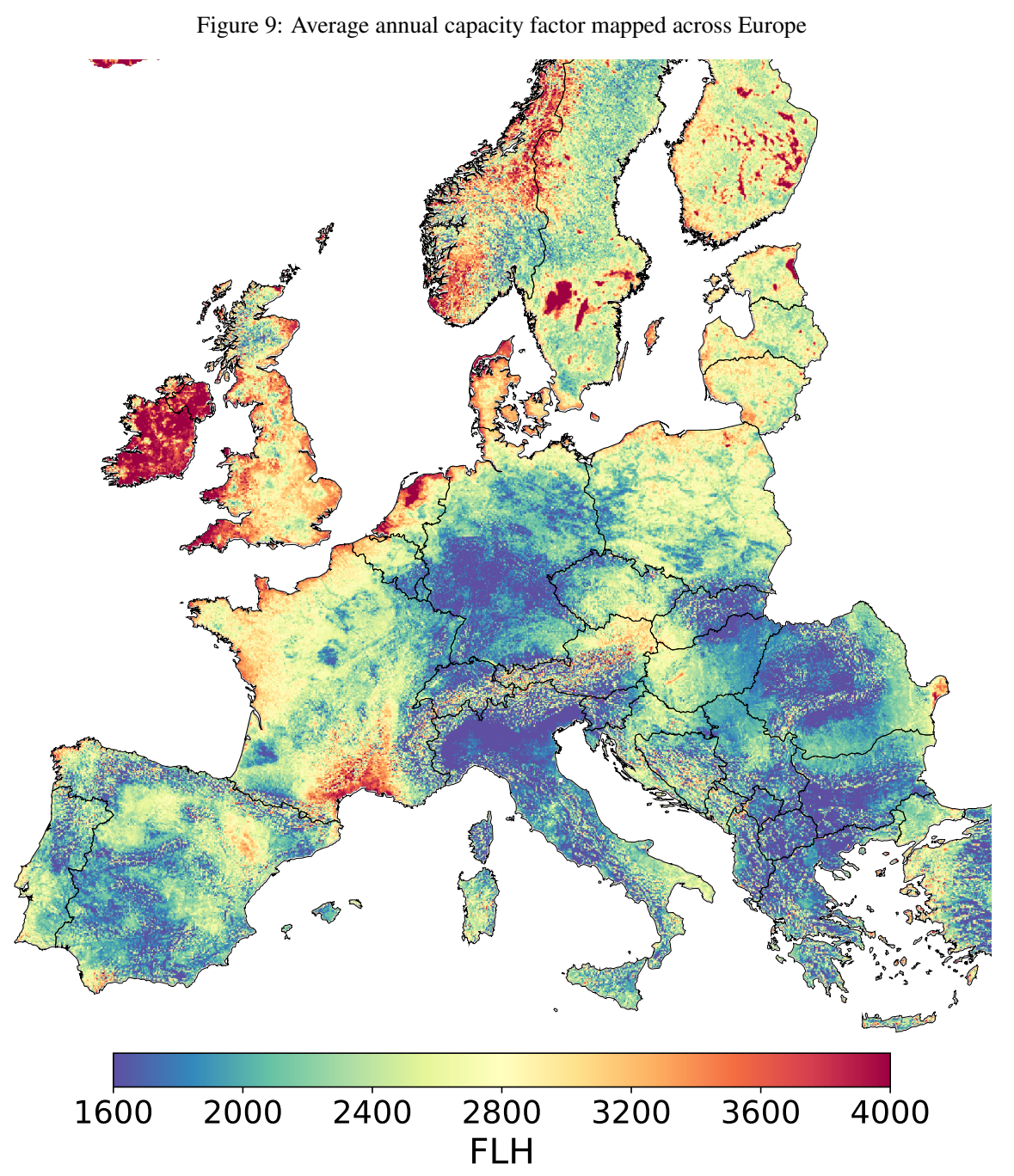

hub height besides their higher FLHs. A large spread of LCOE values are observed, with $90 \%$ of values found between 3.82 and $10.71 €_{\mathrm{ct}} \mathrm{kWh}^{-1}$. Furthermore, an asymmetric distribution is observed, wherein the cheapest cost is observed at $2.33 €_{\mathrm{ct}} \mathrm{kWh}^{-1}$, while the most probable value is found at $5.50 €_{\mathrm{ct}} \mathrm{kWh}^{-1}$, and the average is found at $6.65 €_{\mathrm{ct}} \mathrm{kWh}^{-1}$. These values are not out of range of Wiser et al.'s [37] or JRC's [16] estimations around $4 €_{\mathrm{ct}} \mathrm{kWh}^{-1}$ and $2.8 €_{\mathrm{ct}} \mathrm{kWh}^{-16}$, respectively.

Figure 11 displays results at the country level with locations sorted by LCOE for selected countries ${ }^{7}$. From these figures, it is clear that the FLH performance and cost of wind energy is closely linked to the envisioned capacity. In terms of average FLH, a wide range is observed at low capacities, with Norway possessing the best locations averaging $5367 \mathrm{FLH}$, and Hungary ${ }^{8}$ possessing the worst averaging $3270 \mathrm{FLH}$. The maximum installable capacity is also shown as the right-most point for each line, where France is found to have the largest potential with 1.6 TW, after which Sweden and Spain are nearly tied with potentials of $1.54 \mathrm{TW}$ and $1.53 \mathrm{TW}$. Considering average FLH at the maximum capacity, Ireland leads with 3949 FLH, followed by Denmark at 3331 FLH, and The United Kingdom at

\footnotetext{
${ }^{6}$ when using their provided values in our LCOE computation

${ }^{7}$ Not all countries are shown in the figure, but are nevertheless available in the attached result data

${ }^{8}$ Hungary only possess the worst FLH value at $1 \mathrm{GW}$ for the visualized countries, concerning the full result Luxembourg has the worst $1 \mathrm{GW}$ locations averaging $2352 \mathrm{FLH}$
} 
Figure 10: Average estimated LCOE mapped across Europe with Land eligibility.

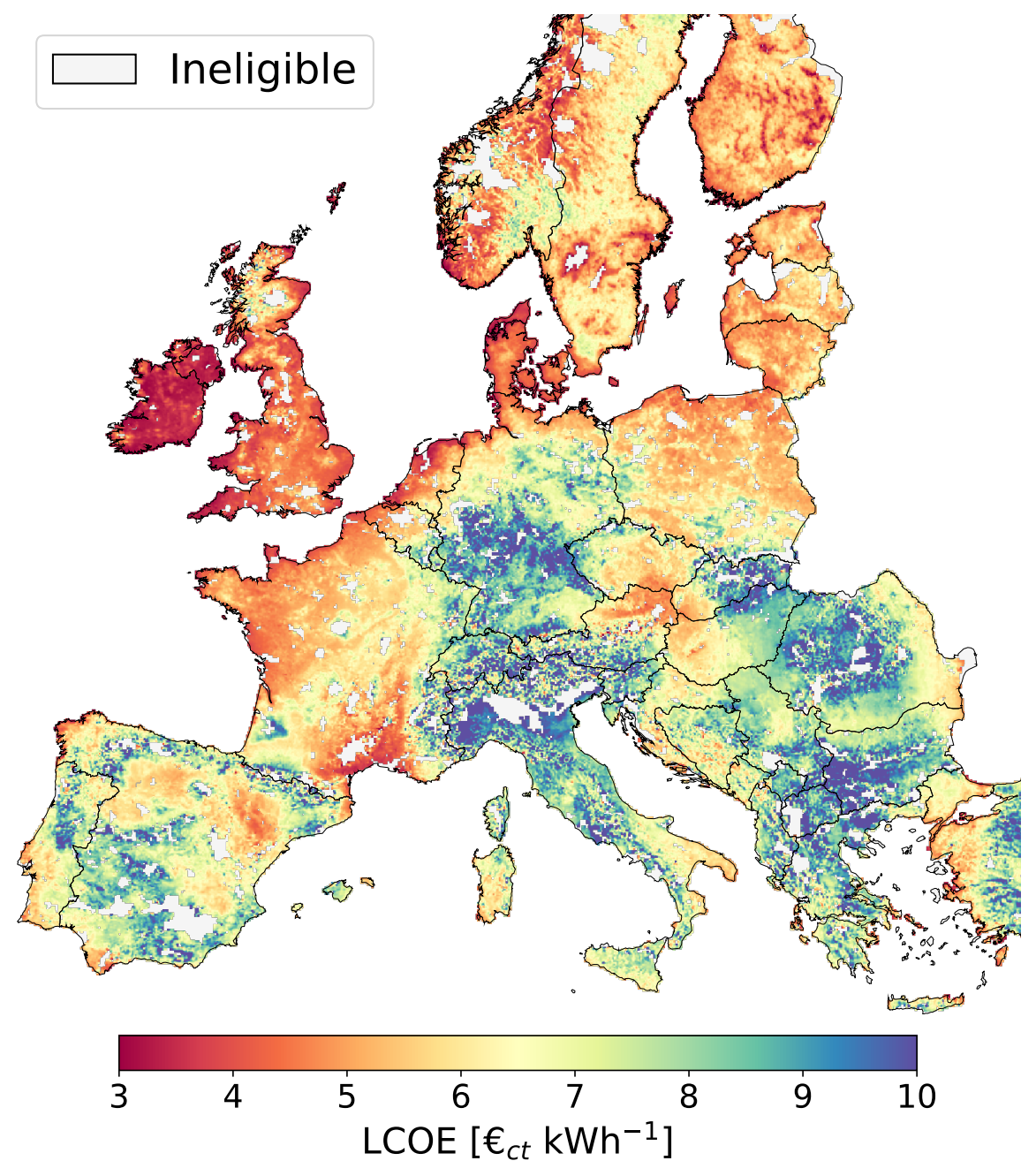

3278 FLH. Meanwhile, Macedonia and Bulgaria (not shown) show the worst performances at 1973 and 1935 FLH, respectively. The greatest spread of FLH is seen in Austria which starts at a potential of 5400 FLH for the first $1 \mathrm{GW}$ of capacity, then falls at rate of roughly $380 \mathrm{FLH}$ for each doubling of the desired capacity until its encompassing potential of $2611 \mathrm{FLH}$ at $166 \mathrm{GW}$. Switzerland also shows a similar FLH fall off rate, as does the latter portions of the trends for Norway and Greece; suggesting that the mountainous ranges in each of these countries can have a drastic impact on the expected performance of wind turbines. For most other countries, in particular France, Germany, Sweden, Belgium, and The Netherlands, a FLH fall of rate between 200 FLH and 250 FLH for each capacity doubling is seen.

In the bottom panes of Figure 11 average LCOE versus a desired capacity is seen where, once again, a very clear relationship is observed between countries with high average FLH and low average LCOE (and vice-versa). Shown in this way, Greece could be considered one of the most expensive countries concerning mean LCOE at maximum capacity, but when much lower capacities are considered costs are competitive. Alongside Greece, the United Kingdom, France, Spain, Norway, Austria, Ireland, Denmark, Sweden, and Finland are all seen to offer some amount of capacity below $3 €_{\mathrm{ct}} \mathrm{kWh}^{-1}$. Of these countries, Norway's potential is the longest lasting, crossing the 3 cent line at an installed capacity of $49.9 \mathrm{GW}$. The close relationship between Germany and Italy is also quite interesting since, although Italy generally has lower wind speeds compared to Germany, the specific turbine designs 
Figure 11: Country level results for average FLH and average LCOE versus a desired capacity. Potentials at each capacity are constituted by the a subset of the locations identified after the land eligibility and placement stages, and are sorted by ascending LCOE.

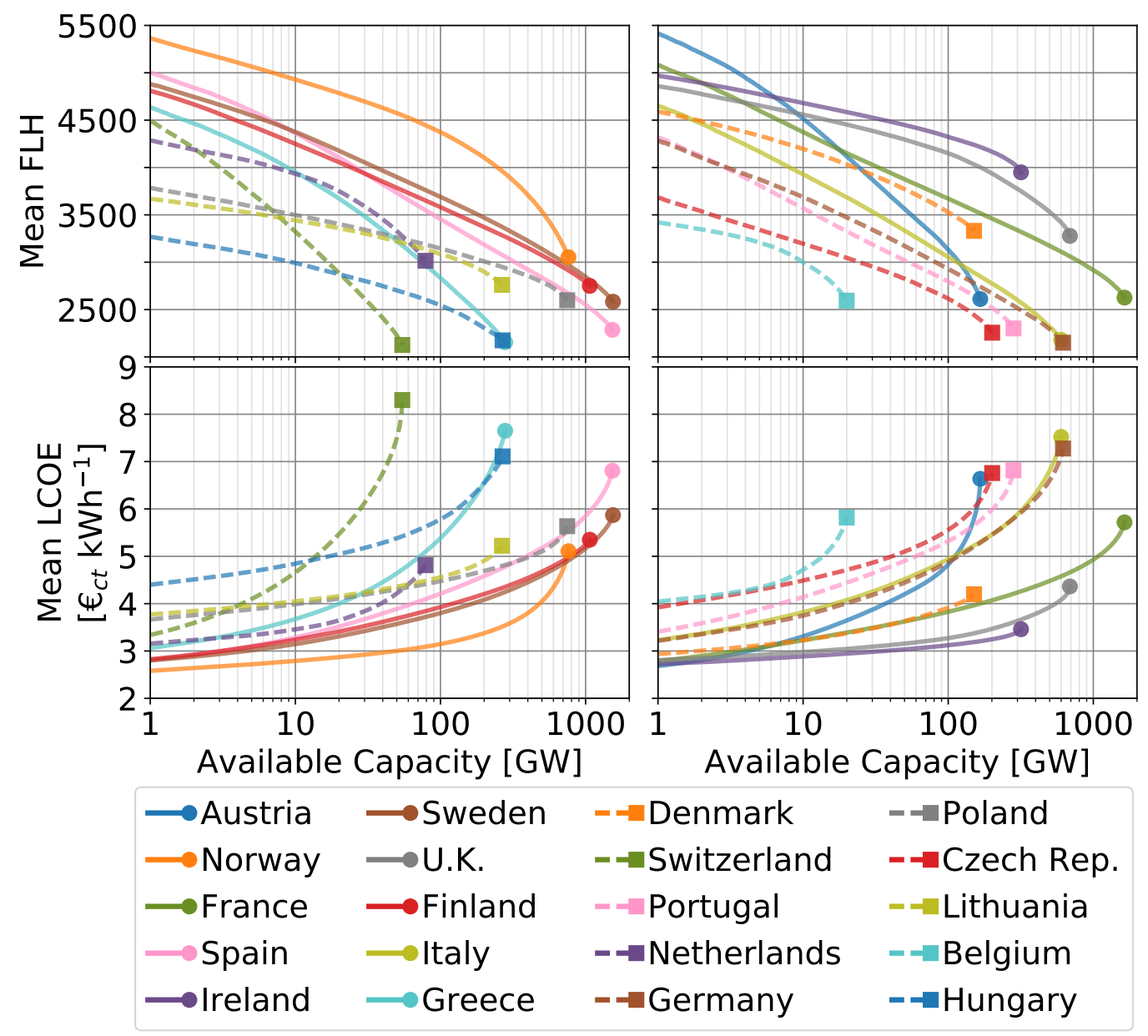

in either country result in nearly equivalent LCOE trends.

For these results locations are sorted by LCOE which, while being unbiased and simple to apply, does not necessarily reflect realistic turbine installation patterns [57]. As a result, capacity-sensitive outcomes of this analysis represent the optimum which could be achieved. Average cost and FLH should remain a function of capacity, but in order to better capture realistic installation selections a multi criterion approach such as that used by Höfer [58], Atici et al. [59], and Aydin [60] could be employed; where distance from settlements, roadways, and power lines, terrain slope, and other parameters are all factored into a location-scoring function alongside the expected performance.

Finally, Table 4 summarizes the available capacity and generation remaining below LCOE limitations of 6 and $4 €_{\mathrm{ct}} \mathrm{kWh}^{-1}$. As mentioned when reviewing Figure 11, France is seen to possess the largest potential for wind capacity and generation when only land eligibility concerns are considered, but when a limitation between a 6 and $4 €_{\mathrm{ct}} \mathrm{kWh}^{-1}$ is imposed this potential drops rapidly; after which Ireland, Norway, the United Kingdom, and Sweden all surpass France's potential. Denmark, Ireland, Finland, Lithuania, and Latvia represent examples where limitations are not impactful until a $4 €_{\mathrm{ct}} \mathrm{kWh}^{-1}$ limitation is considered. In fact, all countries are capable of generating some amount of cheap wind power at or below $4 €_{\mathrm{ct}} \mathrm{kWh}^{-1}$. Beyond this limitation, Ireland is in the top position with $290 \mathrm{GW}$ of potential capacity and $1176 \mathrm{TWh}$ of potential generation, followed by the United Kingdom at $260 \mathrm{GW}$ and $996 \mathrm{TWh}$, and finally Norway at $250 \mathrm{GW}$ and $999 \mathrm{TWh}$.

To put these values into perspective, a short comparison is made against the "100\% RES" scenario from the 


\begin{tabular}{|c|c|c|c|c|c|c|c|}
\hline \multirow[t]{2}{*}{ Region } & \multicolumn{3}{|c|}{ Technical Potential } & \multicolumn{2}{|c|}{$\leq 6 €_{\mathrm{ct}} \mathrm{kWh}^{-1}$} & \multicolumn{2}{|c|}{$\leq 4 €_{\mathrm{ct}} \mathrm{kWh}^{-1}$} \\
\hline & Placements & GW & TWh & GW & TWh & GW & TWh \\
\hline Europe & 3397850 & 13475 & 34434 & 7338 & 22075 & 1177 & 4616 \\
\hline France & 406743 & 1644 & 4310 & 1103 & 3173 & 68 & 256 \\
\hline Sweden & 390439 & 1546 & 3991 & 895 & 2594 & 69 & 262 \\
\hline Spain & 397207 & 1538 & 3504 & 534 & 1502 & 26 & 103 \\
\hline Finland & 266917 & 1077 & 2955 & 851 & 2440 & 48 & 183 \\
\hline Norway & 182681 & 768 & 2332 & 572 & 1951 & 250 & 999 \\
\hline Poland & 182725 & 748 & 1942 & 554 & 1530 & 4.3 & 16 \\
\hline United Kingdom & 153589 & 690 & 2262 & 655 & 2193 & 260 & 996 \\
\hline Germany & 160792 & 620 & 1331 & 145 & 404 & 8.5 & 32 \\
\hline Italy & 163315 & 601 & 1309 & 153 & 443 & 6.8 & 28 \\
\hline Romania & 153103 & 559 & 1166 & 73 & 205 & 2.4 & 10 \\
\hline Ireland & 66267 & 319 & 1257 & 318 & 1255 & 292 & 1176 \\
\hline Portugal & 74375 & 284 & 650 & 98 & 274 & 2.8 & 11 \\
\hline Greece & 75534 & 281 & 603 & 69 & 211 & 8.6 & 35 \\
\hline Serbia & 75692 & 274 & 568 & 31 & 94 & 1.8 & 7.6 \\
\hline Hungary & 71572 & 270 & 585 & 61 & 161 & 0.04 & 0.15 \\
\hline Lithuania & 64539 & 268 & 738 & 226 & 645 & 2.9 & 10 \\
\hline Latvia & 58382 & 239 & 639 & 185 & 519 & 2.8 & 10 \\
\hline Bulgaria & 63893 & 232 & 457 & 20 & 55 & 0.31 & 1.3 \\
\hline Bosnia and Herz. & 56364 & 210 & 506 & 79 & 252 & 15 & 62 \\
\hline Czech Republic & 51112 & 202 & 481 & 96 & 266 & 1.2 & 4.7 \\
\hline Estonia & 43614 & 179 & 496 & 151 & 433 & 6.3 & 23 \\
\hline Austria & 43568 & 166 & 434 & 94 & 298 & 15 & 65 \\
\hline Denmark & 33808 & 151 & 502 & 151 & 502 & 53 & 197 \\
\hline Croatia & 36518 & 136 & 322 & 44 & 129 & 3.3 & 14 \\
\hline Slovakia & 23168 & 86 & 188 & 28 & 80 & 0.71 & 2.9 \\
\hline Netherlands & 18544 & 80 & 239 & 69 & 216 & 19 & 71 \\
\hline Albania & 16033 & 58 & 127 & 15 & 47 & 2.3 & 9.6 \\
\hline Montenegro & 14618 & 56 & 136 & 25 & 77 & 4.0 & 16 \\
\hline Macedonia & 15687 & 56 & 107 & 6.7 & 21 & 0.42 & 1.7 \\
\hline Switzerland & 14968 & 55 & 116 & 13 & 40 & 1.9 & 8.0 \\
\hline Slovenia & 8808 & 31 & 66 & 5.0 & 16 & 0.52 & 2.2 \\
\hline Kosovo & 7641 & 28 & 56 & 4.1 & 13 & 0.48 & 1.9 \\
\hline Belgium & 4937 & 20 & 52 & 13 & 38 & 0.28 & 0.99 \\
\hline Luxembourg & 697 & 2.6 & 5.3 & 0.18 & 0.48 & 0.00 & 0.01 \\
\hline
\end{tabular}

EU's E-Highway project on account of its very high share of installed VRES compared to most other future capacity scenarios. In total $760 \mathrm{GW}$ of onshore wind energy is installed in Europe for this scenario, with the largest shares given to France at $124 \mathrm{GW}$, Germany at $98 \mathrm{GW}$, the United Kingdom at $93 \mathrm{GW}$, Poland with $82 \mathrm{GW}$, Spain at $69 \mathrm{GW}$, and finally Italy with $41 \mathrm{GW}$. In all cases, the prescribed capacities are not within the capacity potentials under the $4 €_{\mathrm{ct}} \mathrm{kWh}^{-1}$ limitation, but are easily contained within the $6 €_{\mathrm{ct}} \mathrm{kWh}^{-1}$ limit. This suggests that future generation costs from onshore wind turbines are likely to be in this range. 


\section{Conclusion}

In this report a wind energy potential estimation method is developed and applied to the European context. Previous estimations have generally employed contemporary turbine designs, sub-optimally exploited available land due to suitability and power density assumptions, or else underestimated wind speeds seen at the strongest wind locations. It is apparent that these previous estimates are likely to under predict both the total amount of wind capacity that could be placed as well as the average FLH of if its operation; thereby doubly under predicting the potential for energy generation due to the use of contemporary turbine design.

Building atop previous studies, the scheme used here implements a highly detailed treatment of land eligibility and explicit turbine placement, and utilizes a validated wind turbine simulation scheme with climate model input. Additionally, a projection is made of future turbine design characteristics across Europe which includes a method to synthetically generate associated turbine power curves. As a result, a total potential estimation for Europe is found at 13.5 TW and 34.3 PWh. Furthermore, all countries show the potential to generate electricity via onshore wind energy below $4 €_{\mathrm{ct}} \mathrm{kWh}^{-1}$, and comparison against future capacity scenarios suggests that future generation costs across Europe are not likely to exceed $6 €_{\mathrm{ct}} \mathrm{kWh}^{-1}$.

Following this work, the procedure can be directly applied to a global scope with appropriate land eligibility data. Moreover, the procedure is applicable for different VRES technologies such as offshore wind and open-field PV with variations to the eligibility constraints and simulation scheme. A sensitivity analysis could be performed to investigate the impact of design and cost assumptions, such as a different baseline turbine or different cost model, or else a climate model with finer resolution could be used as input. Finally, the hourly generation outputs available from this procedure can be used within energy systems design models or else to estimate the length and depth of generation lulls resulting from high shares of onshore wind energy.

\section{Acknowledgements}

- This work was supported by the Helmholtz Association under the Joint Initiative "EnergySystem 2050-A Contribution of the Research Field Energy."

- The authors declare no conflict of interest

\section{Appendix A. Synthetic Power Curve Design}

Figure A.12: Observed turbine power curves in relation to their specific power. A clear relationship is observed in which turbines with small specific powers reach their rater power sooner than turbines with larger specific powers.

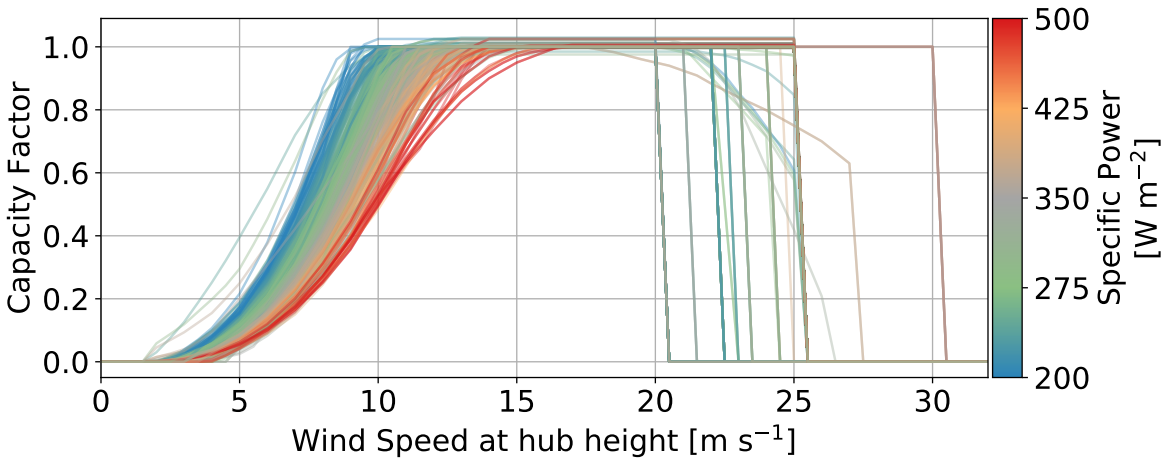

Design of power curves is sensitive to specific power, as shown in Figure A.12. As mentioned in Section 2.1, these power curves were extracted from the Power Curve Database [41], originating from The Wind Power, and includes the power curves of approximately 130 three-bladed, horizontal-axis, upwind, pitch-regulated, onshore wind turbines 
which have capacities larger than $1 \mathrm{MW}$. In order to recreate the trend seen in Figure A.12, a general function is fitted for each $1 \%$ increase in capacity generation between the cut in wind speed and the rated wind speed that returns the expected wind speed at which that capacity generation value should be reached as a function of specific power. The general function which is fitted is shown in Equation A.1, where $v_{i}$ represents the wind speed where capacity factor $c f$ is reached. Example depictions of these fitting functions are shown in Figure A.13, where the general behavior observed was a strong fit nearer to the center of the ramping phase of the power curve, and larger variablility towards the cut-in and rated wind speeds. The fitted constants, $A$ and $B$, are provided in Table A.5.

$$
v_{c f}=\exp (A+B \cdot \ln (\text { specific power }))
$$

Figure A.13: Example depictions of the fitting performed for each $1 \%$ increase in capacity factor during the ramping phase of a wind turbine's power curve. The values at 30 and $70 \%$ show a strong fit between the 160 power curves investigated, while the $1 \%$ and $99 \%$, which are just beyond the cut-in wind speeds and just before the rated wind speed respectively, show a larger spread of observations. Nevertheless, a fitted trend can still be found in all cases.
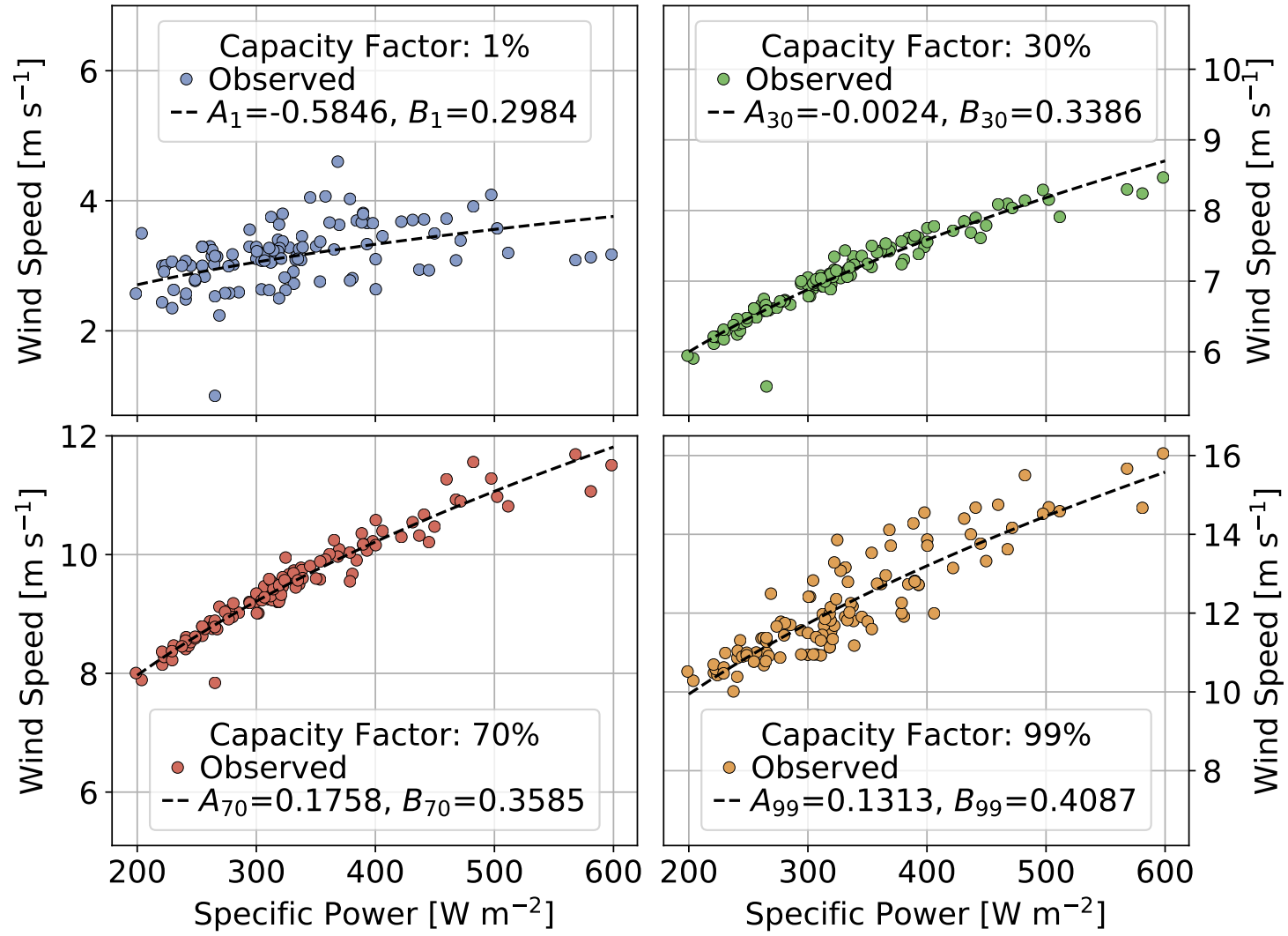

When given a specific power value and a cut out wind speed value, a power curve is designed by computing the wind speed of each capacity factor percentage between the cut-in and rated wind speeds using A and B values from Table A.5 in Equation A.1. Cutin and rated wind speeds are given directly by applying the 0 and 100 percentages constants to Equation A.1. Then, the capacity factor for all wind speeds below the estimated cut-in wind are set to zero, while all capacity factor values between the rated and cut-out wind speeds are set to one. Finally, all capacity factors above the cut-out wind speed are set to zero. At this point, a power curve has been produced and can be used for simulation. 
Table A.5: $A$ and $B$ constant values computed for use in Equation A.1.

\begin{tabular}{|c|c|c|c|c|c|c|c|c|}
\hline$\%$ & $A_{c f}$ & $B_{c f}$ & $\%$ & $A_{c f}$ & $B_{c f}$ & $\%$ & $A_{c f}$ & $B_{c f}$ \\
\hline 1 & -0.584630 & 0.298395 & 35 & 0.089884 & 0.331396 & 69 & 0.179021 & 0.356938 \\
\hline 2 & -0.419940 & 0.288554 & 36 & 0.104825 & 0.330433 & 70 & 0.175836 & 0.358507 \\
\hline 3 & -0.391026 & 0.296708 & 37 & 0.115079 & 0.330222 & 71 & 0.174338 & 0.359783 \\
\hline 4 & -0.389457 & 0.306946 & 38 & 0.119641 & 0.330932 & 72 & 0.172826 & 0.361062 \\
\hline 5 & -0.405802 & 0.318660 & 39 & 0.124266 & 0.331594 & 73 & 0.171831 & 0.362248 \\
\hline 6 & -0.404320 & 0.326210 & 40 & 0.129406 & 0.332135 & 74 & 0.171274 & 0.363357 \\
\hline 7 & -0.392369 & 0.330959 & 41 & 0.135250 & 0.332527 & 75 & 0.171008 & 0.36 \\
\hline 8 & -0.381924 & 0.335307 & 42 & 0.141521 & 0.332818 & 76 & 0.171555 & 0.365349 \\
\hline 9 & -0.363300 & 0.337792 & 43 & 0.146831 & 0.333 & 77 & 0.171 & 329 \\
\hline 10 & -0.343517 & 0.339634 & 44 & 0.151369 & 0.333788 & 78 & 0.171747 & 0.367368 \\
\hline 11 & -0.317832 & 0.339947 & 45 & 0.155791 & 0.33 & 79 & 0.172 & 0.36 \\
\hline 12 & -0.291175 & 0.339762 & 46 & 0.160274 & 0.334814 & 80 & 0.172037 & 0.369401 \\
\hline 13 & -0.269508 & 0.340070 & 47 & 0.16 & 0.33 & 81 & 0.171353 & 0.37 \\
\hline 14 & -0.253212 & 0.341045 & 48 & 0.168360 & 0.335894 & 82 & 0.170385 & 0.371812 \\
\hline 15 & -0.237163 & 0.341822 & 49 & 0.172509 & 0.336394 & 83 & 0.169653 & 0.373019 \\
\hline 16 & & & 50 & & & 84 & & \\
\hline 17 & -0.206083 & 0.343045 & 51 & 0.180574 & 0.337385 & 85 & 0.166319 & 0.375801 \\
\hline 18 & -0.182945 & & 52 & & & 86 & & \\
\hline 19 & -0.159519 & 0.340946 & 53 & 0.188553 & 0.338307 & 87 & 0.163899 & 0.378624 \\
\hline 20 & -0.137017 & & 54 & & & 88 & 0.163928 & 0.379897 \\
\hline 21 & -0.116739 & 0.338917 & 55 & 0.194822 & 0.339454 & 89 & 0.165921 & 0.380865 \\
\hline 22 & -0.101093 & & 56 & 0.197050 & 0.340169 & 90 & 0.168181 & 0.381818 \\
\hline 23 & -0.086576 & 0.338621 & 57 & 0.198232 & 0.341055 & 91 & 0.168264 & 0.383199 \\
\hline 24 & -0.074753 & 0.338868 & 58 & 0.198694 & 0.342060 & 92 & 0.168549 & 0.384629 \\
\hline 25 & -0.063226 & 0.339079 & 59 & 0.198578 & 0.343159 & 93 & 0.171687 & 0.385673 \\
\hline 26 & -0.051254 & 0.339143 & 60 & 0.198261 & 0.344285 & 94 & 0.178577 & 0.386181 \\
\hline 27 & -0.039703 & 0.339222 & 61 & 0.197871 & 0.345417 & 95 & 0.183538 & 0.387207 \\
\hline 28 & -0.028335 & 0.339261 & 62 & 0.196978 & 0.346626 & 96 & 0.178848 & 0.390208 \\
\hline 29 & -0.015586 & 0.339001 & 63 & 0.195416 & 0.347943 & 97 & 0.172858 & 0.393784 \\
\hline 30 & -0.002372 & 0.338596 & 64 & 0.193265 & 0.349355 & 98 & 0.150698 & 0.400896 \\
\hline 31 & 0.012792 & 0.337801 & 65 & 0.190900 & 0.350794 & 99 & 0.131285 & 0.408730 \\
\hline 32 & 0.034139 & 0.335896 & 66 & 0.188335 & 0.352264 & 100 & 0.110124 & 0.421266 \\
\hline 33 & 0.054711 & 0.334097 & 67 & 0.185694 & 0.353743 & & & \\
\hline 34 & 0.073012 & 0.332644 & 68 & 0.182301 & 0.355351 & & & \\
\hline
\end{tabular}

\section{References}

[1] U. Nations, Adoption of the paris agreement. framework convention on climate change, paris (2015).

[2] T. Stocker, D. Qin, G.-K. Plattner, L. Alexander, S. Allen, N. Bindoff, F.-M. Bréon, J. Church, U. Cubasch, S. Emori, P. Forster, P. Fried lingstein, N. Gillett, J. Gregory, D. Hartmann, E. Jansen, B. Kirtman, R. Knutti, K. Krishna Kumar, P. Lemke, J. Marotzke, V. Masson-Delmotte, G. Meehl, I. Mokhov, S. Piao, V. Ramaswamy, D. Randall, M. Rhein, M. Rojas, C. Sabine, D. Shindell, L. Talley, D. Vaughan, S.-P. Xie, Technical Summary, Cambridge University Press, Cambridge, United Kingdom and New York, NY, USA, 2013, book section TS, p. $33-115$. doi:10.1017/CBO9781107415324.005. URL www.climatechange2013.org

[3] S. Chen, M. Ravallion, Communication from the commission to the european parliament, the council, the european economic and social committee and the committee of the regions; energy roadmap 2050, Tech. rep., European Comission (2011). URL https : //eur-lex.europa.eu/LexUriServ/LexUriServ.do?uri=COM : 2011:0885:FIN : EN : PDF

[4] Bundesministerium für Umwelt, Naturschutz, Bau und Reaktorsicherheit (BMUB), Klimaschutzplan 2050 (Nov. 2016). URL http://m.bmu.de/fileadmin/Daten_BMU/Download_PDF/Klimaschutz/klimaschutzplan_2050_bf .pdf

[5] M. Robinius, A. Otto, P. Heuser, L. Welder, K. Syranidis, D. S. Ryberg, T. Grube, P. Markewitz, R. Peters, D. Stolten, Linking the power and transport sectors - Part 1: The principle of sector coupling, Energiesdoi:10.3390/en10070956. 
[6] M. Robinius, A. Otto, K. Syranidis, D. S. Ryberg, P. Heuser, L. Welder, T. Grube, P. Markewitz, V. Tietze, D. Stolten, Linking the power and transport sectors - Part 2: Modelling a sector coupling scenario for Germany, Energies 10 (7). doi:10.3390/en10070957.

[7] G. Thomaßen, M. Deutsch, Future cost of onshore wind. recent auction results, long-term outlook and implications for upcoming german auctions., Tech. rep., Agora Energiewende, Agora Energiewende. Anna-Louisa-Karsch-Straße 2. 10178 Berlin, Germany (April 2017).

URL https://www. agora-energiewende.de/fileadmin2/Projekte/2017/Future_Cost_of_Wind/Agora_Future-Cost-of-Wind_WEB.pdf

[8] B. Möller, Spatial analyses of emerging and fading wind energy landscapes in denmark, Land Use Policy 27 (2) (2010) $233-241$. doi:10.1016/j.landusepol.2009.06.001.

[9] G. Sanchis, Europe's future secure and sustainable electricity infrastructure; e-highway2050 project results, Tech. rep., European Comission (November 2015).

URL http://www.e-highway2050.eu/fileadmin/documents/e_highway2050_booklet.pdf

[10] K. Bruninx, D. Orlic, D. Couckuyt, N. Grisey, B. Betraoui, T. anderski, Y. Surmann, N. T. Franck, G. Keane, B. Hickman, D. Huertashernando, M. Wilk, R. Jankowski, e-highway 2050: Modular development plan of the pan-european transmission system 2050, Tech. rep., European Comission (2014).

URL http://www.e-highway2050.eu/fileadmin/documents/Results/D2_1_Data_sets_of_scenarios_for_2050_20072015.pdf

[11] World energy outlook: 2016, Tech. rep., International Energy Agency, International Energy Agency. 9 rue de la Fédération. 75739 Paris Cedex 15, France (2016).

URL https://www. iea.org/newsroom/news/2016/november/world-energy-outlook-2016.html

[12] L. Fried, S. Shukla, S. Sawyer, S. Teske, Global wind energy outlook: 2016, Tech. rep., Global Wind Energy Council (Oct. 2016). URL http://files.gwec.net/files/GlobalWindEnergyOutlook2016

[13] Roadmap 2050: A practical guide to a prosperous, low-carbon europe, Tech. rep., European Climate Foundation (ECF) (2010). URL http://www.roadmap2050.eu/attachments/files/Volume1_fullreport_PressPack.pdf

[14] A. Ilas, P. Ralon, A. Rodriguez, M. Taylor, Renewable power generation costs in 2017, Tech. rep., International Renewable Energy Agency (IRENA), ISBN 978-92-9260-040-2 (2018).

URL https://www.irena.org/-/media/Files/IRENA/Agency/Publication/2018/Jan/IRENA_2017_Power_Costs_2018.pdf

[15] P. Nielsen, Vindmøllers Økonomi, Tech. rep., EMD International, UEDP projekt 33033-0196 (2010).

[16] R. Lacal Arantegui, A. Jaeger-waldau, M. Vellei, B. Sigfusson, D. Magagna, M. Jakubcionis, M. Perez Fortes Del Mar, S. Lazarou, J. Giuntoli, E. Weidner Ronnefeld, G. De Marco, A. Spisto, C. Gutierrez Moles, ETRI 2014 - Energy Technology Reference Indicator projections for 2010-2050, Tech. rep., Joint Research Center (2014). doi:10.2790/057687. URL http://publications.jrc.ec.europa.eu/repository/handle/JRC92496

[17] G. H. Oettinger, Energy roadmap 2050, Tech. rep., European Comission (2012). doi:10.2833/10759. URL https://ec.europa.eu/energy/en/topics/energy-strategy-and-energy-union/2050-energy-strategy

[18] M. Taylor, P. Ralon, A. Ilas, The power to change: Solar and wind cost reduction potential to 2025, Tech. rep., International Renewable Energy Agency (IRENA), iSBN: 978-92-95111-97-4 (2016).

URL http://www.irena.org/-/media/Files/IRENA/Agency/Publication/2016/IRENA_Power_to_Change_2016.pdf

[19] M. Robinius, Strom- und Gasmarktdesign zur Versorgung des deutschen Straßenverkehrs mit Wasserstoff Von der Fakultät für Maschinenwesen der Rheinisch-Westfälischen Technischen Hochschule Aachen zur Erlangung des akademischen Grades eines Doktors der Ingenieurwissensch, Doctoral, RWTH Aachen (2015).

[20] I. Gonzalez Aparicio, A. Zucker, F. Careri, F. Monforti, T. Huld, J. Badger, EMHIRES dataset. Part I: Wind power generation European Meteorological derived HIgh resolution RES generation time series for present and future scenarios, Tech. rep., Joint Research Center (2016). doi:10.2790/831549.

URL https://setis.ec.europa.eu/sites/default/files/reports/emhires_dataset_part_i_wind_power_generation_0.pdf

[21] W. Zappa, M. van den Broek, Analysing the potential of integrating wind and solar power in Europe using spatial optimisation under various scenarios, Renewable and Sustainable Energy Reviews 94 (August) (2018) 1192-1216. doi:10.1016/j.rser.2018.05.071.

URL https://doi.org/10.1016/j.rser.2018.05.071

[22] I. Staffell, S. Pfenninger, Using bias-corrected reanalysis to simulate current and future wind power output, Energy 114 (2016) $1224-1239$.

[23] J. Bosch, I. Staffell, A. D. Hawkes, Temporally-explicit and spatially-resolved global onshore wind energy potentials, Energy 131 (2017) 207-217. doi:10.1016/j.energy.2017.05.052.

[24] R. McKenna, S. Hollnaicher, P. O. vd Leye, W. Fichtner, Cost-potentials for large onshore wind turbines in Europe, Energy 83 (2015) $217-229$.

[25] I. Lütkehus, K. Adlunger, H. Salecker, Potenzial der windenergie an land: Studie zur ermittlung des bundesweiten flächen-und leistungspotenzials der windenergienutzung an land, Tech. rep., Umweltbundesamt (2013).

[26] DTU Wind Energy, World Bank Group, Global Wind Atlas 1.0: Methodology (2018).

URL http://science.globalwindatlas.info/methods.html

[27] Y. Zhang, D. J. Seidel, S. Zhang, Trends in Planetary Boundary Layer Height over Europe, Journal of Climate 26 (24) (2013) $10071-10076$. doi:10.1175/jcli-d-13-00108.1.

[28] D. S. Ryberg, Z. Tulemat, D. Stolten, M. Robinius, Uniformly Constrained Land Eligibility for Onshore European Wind Power, Renewable EnergyUnder Review [Submitted June 2018].

[29] D. S. Ryberg, Z. Tulemat, M. Robinius, D. Stolten, Geospatial Land Availability for Energy Systems (GLAES), GitHub Repository (2017). URL http//github.com/FZJ-IEK3-VSA/glaes

[30] D. S. Ryberg, M. Robinius, D. Stolten, Evaluating Land Eligibility Constraints of Renewable Energy Sources in Europe, Energies 11 (5). doi:10.3390/en11051246.

URL http://www . mdpi . com/1996-1073/11/5/1246

[31] T. Jäger, R. McKenna, W. Fichtner, The feasible onshore wind energy potential in baden-württemberg: a bottom-up methodology considering socio-economic constraints, Renewable Energy 96 (2016) 662-675.

[32] A. Emami, P. Noghreh, New approach on optimization in placement of wind turbines within wind farm by genetic algorithms, Renewable 
Energy 35 (7) (2010) 1559-1564.

[33] R. McKenna, S. Hollnaicher, W. Fichtner, Cost-potential curves for onshore wind energy: A high-resolution analysis for germany, Applied Energy 115 (2014) 103-115.

[34] I. E. Commission, et al., Iec 61400-1: Wind turbines part 1: Design requirements, International Electrotechnical Commission.

[35] Iea wind, task 26: Data viewer, Online (2018). URL https://community. ieawind.org/task26/dataviewer

[36] A. Dalla Riva, J. Hethey, A. Vītina, Impacts of wind turbine technology on the system value of wind in europe, Tech. rep., International Energy Agency (2017). doi:NREL/TP-6A20-70337. URL https://www.nrel.gov/docs/fy18osti/70337.pdf

[37] R. Wiser, K. Jenni, J. Seel, E. Baker, M. Hand, E. Lantz, A. Smith, Expert elicitation survey on future wind energy costs, Nature Energy 1 (10) (2016) 16135.

[38] V. W. Systems, Vestas 4mw platform, accessed May, 2018 (2017). URL http://nozebra.ipapercms.dk/Vestas/Communication/Productbrochure/4MWbrochure/4MWProductBrochure/

[39] The Wind Power, World wind farms database, Dataset, accessed: 2017-11-01 (2018). URL https: //www. thewindpower.net/store_continent_en.php?id_zone $=1000$

[40] Technical University of Denmark, DTU Global Wind Atlas 1km resolution [Dataset], online, accessed: 2017-04-01 (2015). URL https : //irena.masdar.ac.ae/gallery/\#map/103

[41] The Wind Power, Power curves database, Dataset, accessed: 2017-11-01 (2017). URL https://www.thewindpower.net/store_manufacturer_turbine_en.php?id_type=7

[42] J. Silva, C. Ribeiro, R. Guedes, Roughness length classification of corine land cover classes, megajoule Consultants (Jan 2007).

[43] C. IEC, 61400-12-1: Wind turbines-part 12-1: Power performance measurements of electricity producing wind turbines, Geneva, Switzerland: IEC.

[44] H. J. Wagner, J. Mathur, Introduction to Wind Energy Systems: Basics, Technology and Operation, Springer Science \& Business Media, 2009.

[45] G. Smart, A. Smith, E. Warner, I. Bakken Sperstad, B. Prinsen, R. Lacal-Arántegui, Iea wind task 26 - offshore wind farm baseline documentation, Tech. rep., IEA Wind (2016). doi:NREL/TP-6A20-66262. URL www.nrel.gov/docs/fy16osti/66262.pdf

[46] L. J. Fingersh, M. Hand, A. Laxson, L. J. Fingersh, M. Hand, A. Laxson, Wind Turbine Design Cost and Scaling Model, Tech. rep., National Renewable Energy Agency, Golden, Colorado. USA (2006). doi:10.1016/j.advwatres.2006.01.003.

[47] B. Maples, M. Hand, W. Musial, Comparative assessment of direct drive high temperature superconducting generators in multi-megawatt class wind turbines, Tech. rep., National Renewable Energy Lab.(NREL), Golden, CO (United States) (2010).

[48] T. J. Stehly, D. M. Heimiller, G. N. Scott, 2016 cost of wind energy review, Tech. rep., National Renewable Energy Lab.(NREL), Golden, CO (United States) (2017).

[49] J. M. P. Pérez, F. P. G. Márquez, A. Tobias, M. Papaelias", Wind turbine reliability analysis, Renewable and Sustainable Energy Reviews 23 (2013) 463 - 472. doi:https://doi.org/10.1016/j.rser.2013.03.018.

URL "http://www.sciencedirect.com/science/article/pii/S1364032113001779"

[50] European Energy Exchange (EEX), Transparency in Energy Markets, online, accessed: 2017-08-23. (2017).

URL https://www.eex.com/de/about/eex/transparency-in-energy-markets

[51] ENGIE Group, la-haute-borne-data-2013-2016 [Dataset], online, accessed: 2018-03-01. License: Licence Ouverte v2.0 (Etalab) (2017). URL https://opendata-renewables.engie.com/explore/dataset/la-haute-borne-data-2013-2016/

[52] ENGIE Group, La Haute Borne static information [Dataset], online, accessed: 2018-03-01. License: Licence Ouverte v2.0 (Etalab) (2017). URL https://opendata-renewables .engie.com/explore/dataset/static-information/

[53] Danish Energy Agency, Master Data Register of Wind Turbines, online, accessed: 2017-10-19. (2017). URL "https://ens.dk/en/our-services/statistics-data-key-figures-and-energy-maps/overview-energy-sector"

[54] C. Coppens, H. Gordijn, M. Piek, P. Ruyssenaars, J.-j. Schrander, P. de Smet, R. Swart, M. Hoogwijk, M. Papalexandrou, E. de Visser, J. Horalek, P. Kurfürst, F. Pagh Jensen, B. Svenning Petersen, M. Harfoot, R. Milego, N.-E. Clausen, G. Giebel, Europe's onshore and offshore wind energy potential: An assessment of environmental and economic constraints, Report, European Environmental Agency (June 2009). doi:10.2800/11373.

[55] UNEP-WCMC and IUCN. Cambridge, UK, Protected Planet: The World Database on Protected Areas (WDPA)[On-Line], Available at: www.protectedplanet.net, accessed: 2017-04-01 (2016).

[56] International Energy Agency, Energy Technology Perspectives 2017 - Executive Summary, Tech. rep., International Energy Agency (2017). arXiv:IEA, 2016, doi:10.1787/energy_tech-2014-en.

[57] K. Rehfeldt, L. Rehfeldt, P. Graichen, Vergütung von Windenergieanlagen an Land über das Referenzertragsmodel, Tech. rep., Agora Energiewende (March 2014).

URL https://www. agora-energiewende.de/fileadmin/Projekte/2012/Studie_Referenzertragsmodell_Wind_korrigiert_WEB.pdf

[58] T. Höfer, Y. Sunak, H. Siddique, R. Madlener, Wind farm siting using a spatial analytic hierarchy process approach: A case study of the städteregion aachen, Applied Energy 163 (2016) 222-243. doi:10.1016/j.apenergy.2015.10.138.

[59] K. B. Atici, A. B. Simsek, A. Ulucan, M. U. Tosun, A gis-based multiple criteria decision analysis approach for wind power plant site selection, Utilities Policy 37 (2015) 86-96. doi:10.1016/j.jup.2015.06.001.

[60] N. Y. Aydin, E. Kentel, H. S. Duzgun, Gis-based site selection methodology for hybrid renewable energy systems: A case study from western turkey, Energy Conversion and Management 70 (2013) 90-106. doi:10.1016/j.enconman.2013.02.004. 